\title{
Potential Role of Photosynthesis in the Regulation of Reactive Oxygen Species and Defence Responses to Blumeria graminis f. sp. tritici in Wheat
}

\author{
Yuting $\mathrm{Hu}{ }^{1,2}$, Shengfu Zhong ${ }^{1}$, Min Zhang ${ }^{2, *}$, Yinping Liang ${ }^{1}$, Guoshu Gong ${ }^{1}$, Xiaoli Chang ${ }^{1}$, \\ Feiquan Tan ${ }^{1}$, Huai Yang ${ }^{1}$, Xiaoyan Qiu ${ }^{2}$, Liya Luo ${ }^{2}$ and Peigao Luo ${ }^{1, *(B)}$ \\ 1 Provincial Key Laboratory of Plant Breeding and Genetics, College of Agronomy, Sichuan Agricultural \\ University, Chengdu 611130, Sichuan, China; yutinghu@stu.sicau.edu.cn (Y.H.); \\ zhongsicau@gmail.com (S.Z.); liangyinping3@163.com (Y.L.); guoshugong@126.com (G.G.); \\ xl_changkit@126.com (X.C.); FeiquanTan_1@163.com (F.T.); yanghuaiv@163.com (H.Y.) \\ 2 College of Agronomy \& Key Laboratory for Major Crop Diseases, Sichuan Agricultural University, \\ Chengdu 611130, Sichuan, China; qxytzp@163.com (X.Q.); scmlsjc@163.com (L.L.) \\ * Correspondence: yalanmin@126.com (M.Z.); lpglab@sicau.edu.cn (P.L.)
}

Received: 20 July 2020; Accepted: 8 August 2020; Published: 11 August 2020

\begin{abstract}
Photosynthesis is not only a primary generator of reactive oxygen species (ROS) but also a component of plant defence. To determine the relationships among photosynthesis, ROS, and defence responses to powdery mildew in wheat, we compared the responses of the $P m 40$-expressing wheat line L658 and its susceptible sister line L958 at 0, 6, 12, 24, 48, and $72 \mathrm{~h}$ post-inoculation (hpi) with powdery mildew via analyses of transcriptomes, cytology, antioxidant activities, photosynthesis, and chlorophyll fluorescence parameters. The results showed that $\mathrm{H}_{2} \mathrm{O}_{2}$ accumulation in L658 was significantly greater than that in L958 at 6 and $48 \mathrm{hpi}$, and the enzymes activity and transcripts expression of peroxidase and catalase were suppressed in L658 compared with L958. In addition, the inhibition of photosynthesis in L658 paralleled the global downregulation of photosynthesis-related genes. Furthermore, the expression of the salicylic acid-related genes non-expressor of pathogenesis related genes 1 (NPR1), pathogenesis-related 1 (PR1), and pathogenesis-related 5 (PR5) was upregulated, while the expression of jasmonic acid- and ethylene-related genes was inhibited in L658 compared with L958. In conclusion, the downregulation of photosynthesis-related genes likely led to a decline in photosynthesis, which may be combined with the inhibition of peroxidase (POD) and catalase (CAT) to generate two stages of $\mathrm{H}_{2} \mathrm{O}_{2}$ accumulation. The high level of $\mathrm{H}_{2} \mathrm{O}_{2}$, salicylic acid and PR1 and PR5 in L658 possible initiated the hypersensitive response.
\end{abstract}

Keywords: wheat powdery mildew; photosynthesis; reactive oxygen species; plant defence; salicylic acid; transcriptomics

\section{Introduction}

Plants are challenged by various biotic stresses, including viral, bacterial, and fungal pathogenic stresses, which have substantial economic and ecological impacts [1,2]. Plants depend on their innate immune system to perceive and respond to biotic stimuli [3]. The first line of the immune response is called pathogen-associated molecular pattern (PAMP)-triggered immunity (PTI), which is triggered by various PAMPs [4]. During this period, the physiological and biochemical statuses of plants correspondingly change, which include phenomena such as cytoskeletal reorganization, cell wall reinforcement, reactive oxygen species (ROS) bursts, and stomatal closure [5-7]. To defend against pathogens further, resistance $(R)$ proteins of plants recognize specific effectors generated by pathogens in the infection process to trigger the second line of defence referred to as effector-triggered immunity 
(ETI) [4]. These defence responses include expression of pathogenesis-related $(P R)$ genes and initiation of the hypersensitive response (HR) to restrict biotrophic pathogen growth $[4,8]$. ETI may also trigger systemic acquired resistance (SAR) responses in distal uninfected tissues [9,10]. Although PTI and ETI responses are triggered by different pathogen-derived molecules, they share several downstream signals, including ROS and phytohormones [11]. The signaling overlap between PTI and ETI suggests that they are complementary, however, the differences in the strength or timing of signals lead to differences in defence strength [12]. In this process, chloroplasts, as the main production sites of ROS and phytohormones, are considered to be an important battleground for the interaction between hosts and pathogens $[13,14]$.

In general, ROS are composed mainly of singlet oxygen $\left({ }^{1} \mathrm{O}_{2}\right)$, superoxide anion radical $\left(\mathrm{O}^{2 \bullet-}\right)$, hydrogen peroxide $\left(\mathrm{H}_{2} \mathrm{O}_{2}\right)$, and hydroxyl radical $(\bullet \mathrm{OH})[15,16]$. In plants, ROS are produced mainly by photosystem I (PSI) and photosystem II (PSII) during photosynthesis [17]. On the one hand, ground-state oxygen $\left({ }^{3} \mathrm{O}_{2}\right)$ is continuously excited to produce ${ }^{1} \mathrm{O}_{2}$ in the PSII reaction centre [18,19]. On the other hand, $\mathrm{O}_{2}$ is reduced to $\mathrm{O}^{2 \cdot-}$ directly by electron transport and electron leakage from the acceptor side (QA and QB) of PSI and PSII, respectively $[20,21]$. Finally, $\mathrm{O}^{2 \boldsymbol{\bullet}-}$, which presents high reactivity and short life, is easily dismutated to $\mathrm{H}_{2} \mathrm{O}_{2}$ by superoxide dismutase (SOD) [22] . Traditionally, ROS are considered inevitably harmful by-products during aerobic metabolism. In fact, ROS, especially $\mathrm{H}_{2} \mathrm{O}_{2}$, not only have basic defence functions but also act as second messengers to activate the expression of defence genes [23]. Various studies have demonstrated that $\mathrm{H}_{2} \mathrm{O}_{2}$ could be both a signal molecule that induces defence responses at low/moderate concentrations and a defensive weapon to resist pathogen infection directly at high concentrations [16,23]. The concentration of $\mathrm{H}_{2} \mathrm{O}_{2}$ can be rapidly and precisely regulated by various antioxidant enzymes, mainly SOD, catalase (CAT), peroxidase (POD), and ascorbate peroxidase (APX), with CAT acting as a key $\mathrm{H}_{2} \mathrm{O}_{2}$-scavenging enzyme and playing a particularly crucial role in regulating $\mathrm{H}_{2} \mathrm{O}_{2}$ concentrations [16]. Overall, whether $\mathrm{H}_{2} \mathrm{O}_{2}$ acts as a signaling molecule or as a defensive weapon relies on the precise regulation between $\mathrm{H}_{2} \mathrm{O}_{2}$ production and scavenging, and the different interplay between $\mathrm{H}_{2} \mathrm{O}_{2}$-producing and $\mathrm{H}_{2} \mathrm{O}_{2}$-scavenging pathways during stress determines the different kinds of defence responses put forth by plants and their tolerance to stress $[16,24]$.

In addition to $\mathrm{H}_{2} \mathrm{O}_{2}$, phytohormones such as salicylic acid (SA), jasmonic acid (JA), and ethylene (ET), which are mainly synthesized in chloroplasts, also play important roles in the regulation of different defence responses [13]. In host plants, the biosynthesis of ET includes the following three steps: firstly, s-adenosine Met (SAM) synthetase converts methionine (Met) into SAM; secondly, SAM is converted into 1-aminocyclopropane-1-carboxylic acid (ACC) by ACC synthase; finally, ACC oxidase (ACO) catalyses ACC to ET. The precursor for ET biosynthesis, methionine, is produced in the chloroplast [19]. In addition, linolenic acid released from chloroplast membranes is the substrate of JA biosynthesis [13]. Moreover, the isochorismate synthase (ICS) pathway, which is one of the major contributors to SA synthesis from chorismate, is localized in the chloroplast as well [25]. It is well known that there is a mutually antagonistic interaction between SA- and JA/ET-dependent signaling against distinct pathogens that have different lifestyles [4]. For example, biotrophic pathogens are inhibited mainly by SA-mediated defences, whereas defences against necrotrophic pathogens are regulated by JA/ET [26]. Furthermore, some studies have suggested that there is an interplay between plant hormones and both photosynthesis and $\mathrm{H}_{2} \mathrm{O}_{2}[24,27,28]$. For instance, the expression of photosynthesis-related genes is universally downregulated under biotic stress while the expression of genes involved in the synthesis of JA, SA, and ET is upregulated, which indicates that the downregulated expression of photosynthesis-related genes is part of the defence response [29]. Furthermore, SA can inhibit $\mathrm{H}_{2} \mathrm{O}_{2}$-scavenging enzymes, such as CAT and APX [30,31], and in turn, $\mathrm{H}_{2} \mathrm{O}_{2}$ accumulation in the chloroplast can result in elevated SA levels and enhanced SA responses [32].

In addition to indirectly participating in plant defence, some photosynthesis-related proteins can directly interact with pathogens to regulate defence responses. For example, Arabidopsis PsbP, a PSII subunit, interacts with the coat protein of Alfalfa mosaic virus to inhibit viral replication [33]. 
The electron acceptor protein ferredoxin-I (Fd-I) is associated with the production of ROS and the HR in defence against Pseudomonas syringae in sweet pepper [34], and the overexpression of the Fd-I gene also confers enhanced resistance to virulent bacteria in other plants [35-38]. In fact, light-harvesting chlorophyll a/b-binding proteins (LHCBs) also partly modulate ROS homeostasis to affect abscisic acid (ABA) signaling [39]. Furthermore, some pathogen effectors, such as P. syringae HopI1 and HopN1, interact with the oxygen-evolving complex PsbQ of PSII and target chloroplast-localized heat shock protein Hsp70, respectively, to supress immunity reactions, including the suppression of SA accumulation and the reduction of ROS production and cell death [40,41]. Furthermore, some photorespiratory genes are involved in plant defence response as well [42,43]. For instance, silencing of photorespiration-related gene glycolate oxidase (GOX) in Nicotiana benthamiana increased susceptibility to $P$. syringae and Xanthomonas campestris. Furthermore, Arabidopsis gox mutants exhibited a reduction in $\mathrm{H}_{2} \mathrm{O}_{2}$ accumulation after P. syringae infection [44]. In tomato, GOX2 and another two photorespiratory genes serine glyoxylate aminotransferase (SGT) and serine hydroxyl methyltransferase (SHMT1) positively regulated the defence response against $P$. syringae. $\mathrm{H}_{2} \mathrm{O}_{2}$ accumulation plays critical role in GOX2-regulated but not SGT-regulated and SHMT1-regulated SA signaling [45]. These studies indicate that photosynthesis-related proteins combined with both ROS and phytohormones play a central role in plant defence.

Wheat powdery mildew, caused by the obligate biotrophic fungus Blumeria graminis f. sp. tritici $(B g t)$, is a destructive wheat disease worldwide [46,47]. The wheat powdery mildew resistance gene Pm40 originally derived from Elytrigia intermedia was mapped onto chromosome arm 7BS. This gene is associated with strong resistance against various Bgt strains and has been widely used in Chinese wheat breeding programmes [48-50]. Our pfrevious studies suggested that components associated with photosynthesis, especially the PSII reaction centre, were important sites for Pm40-mediated resistance, and some photosynthesis-related proteins, early ROS accumulation, papilla formation, and defence-related gene expression are involved in resistance [51-53].

RNA sequencing (RNA-seq) is an effective and powerful method for investigating pathogen infection, host defence and plant-pathogen interaction mechanisms. In our previous study, we compared the transcriptome of Bgt during interactions with the Pm40-expressing wheat line L658 and the Pm40-deficient sister line L958 to determine the pathogenesis of Bgt [54]. In this study, we further analysed the sequencing data with a focus on determining the resistance responses of the host from the other standpoint. In addition, differences between the two genotypes were revealed via light microscopy and antioxidant enzyme activities, and photosynthesis and chlorophyll fluorescence parameters were measured at various time points to further elucidate the relationships among photosynthesis, ROS, and plant hormones in wheat during the response to Bgt.

\section{Results}

\subsection{Transcriptome Analysis of L658 and L958 during Bgt Infection}

In our previous study, differences in the infection mechanism of Bgt during the interactions with L658 and L958 were determined [54]. To further clarify the difference in the molecular response mechanisms between L658 and L958, we continued to analyse the RNA-seq data from the plant side. Briefly, the percentage of reads mapped to the wheat reference genome was high for all samples and the smallest percentage of mapped reads reached $84.69 \%$, with 21 out of 36 percentages higher than $90 \%$ (Table S1). Furthermore, we screened the differentially expressed genes (DEGs) between the two genotypes at the same time point and the maximal DEG number was 2087 at $12 \mathrm{~h}$ post-inoculation (hpi) (Figure 1A). In addition, we also screened the DEGs in the same genotype at each inoculation time point compared with the uninoculated time point $(0 \mathrm{~h})$, and between two adjacent time points (Figure 1B). Interestingly, a large portion of these DEGs were the same in both L658 and L958 (shown as overlaps), and the expression trend of nearly all of them was the same (Figure 1B), which could be explained by their similar genetic background. To validate the reliability of the transcriptome data, 12 randomly 
selected genes were analysed via quantitative real-time PCR (qRT-PCR) (Table S2). The correlation between normalized RNA-seq reads per kilobase per million (RPKM) values and normalized expression values from qRT-PCR was high $\left(\mathrm{R}=0.8366, p\right.$-value $\left.=1.12 \times 10^{-38}\right)$, which confirmed the reliability of RNA-seq data (Figure 1C).

A
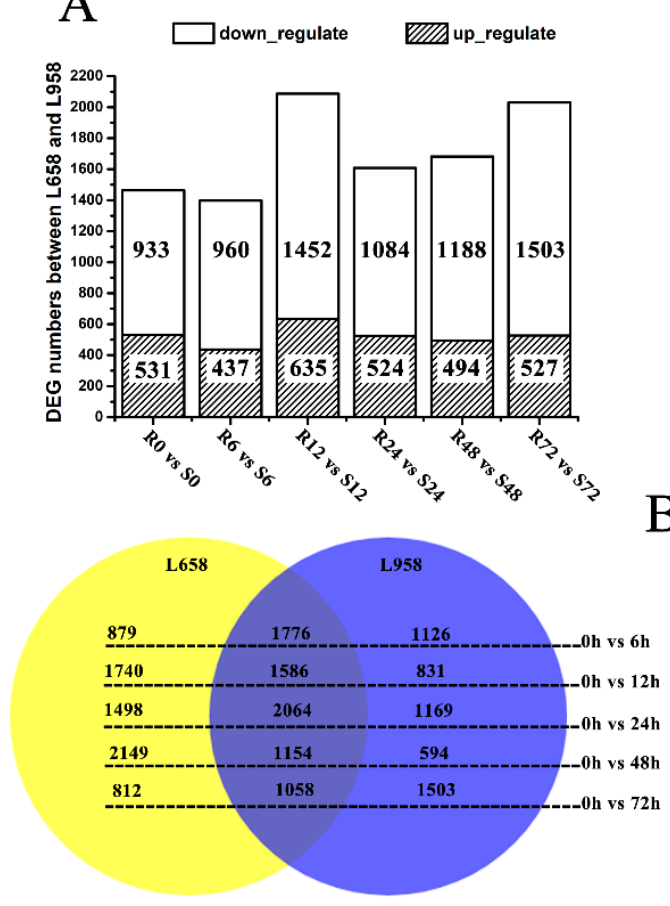

$\mathrm{C}$

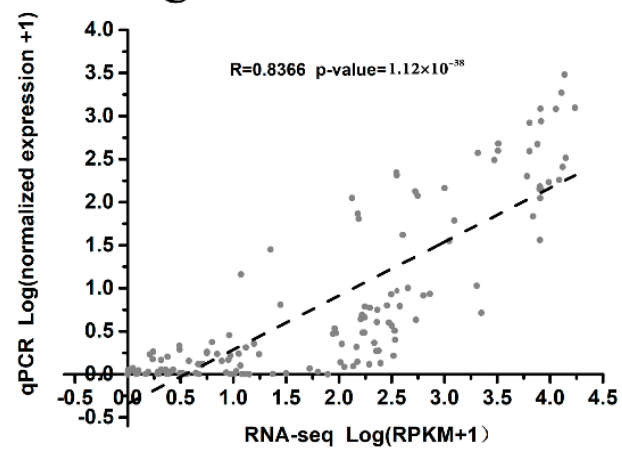

B

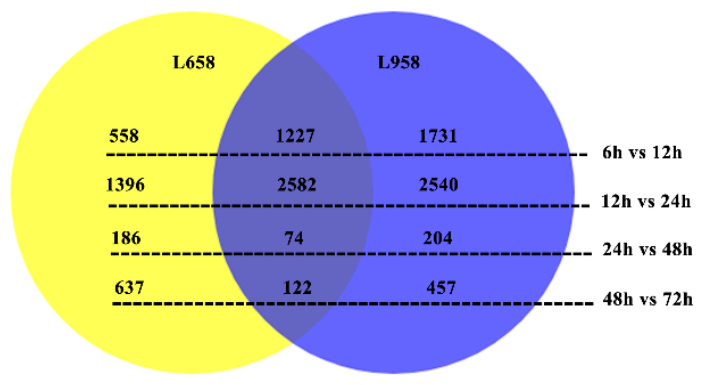

Figure 1. Number of differentially expressed genes (DEGs) in different comparisons and reliability of RNA-seq data as demonstrated by quantitative real-time PCR (qRT-PCR). (A) Number of DEGs between L658 (R) and L958 (S) at different inoculation time points; (B) Venn diagram showing the number of DEGs shared between (overlap) and specific to L658 (yellow) and L958 (blue) at various inoculation time points compared with $0 \mathrm{~h}$ (left) and between two adjacent time points (right); and (C) correlations between normalized RNA-seq reads per kilobase per million (RPKM) values and normalized qRT-PCR expression values. The scatterplot shows the $\log 10$ of RPKM values +1 and the $\log 10$ of qRT-PCR expression values +1 ; a trend line is shown as the dotted line.

\subsection{Difference in $\mathrm{H}_{2} \mathrm{O}_{2}$ Accumulation and Related DEG Expression between L658 and L958}

$\mathrm{H}_{2} \mathrm{O}_{2}$ accumulation is a typical host defence response to biotrophic fungi [4]. In this study, the results of $3^{\prime}$-diaminobenzidine (DAB) staining showed that $\mathrm{H}_{2} \mathrm{O}_{2}$ similarly accumulated under primary germ tube (PGT) at 6 and 12 hpi and then accumulated under penetration peg (PP) at $24 \mathrm{hpi}$ in both L658 and L958 (Figure 2A,B). Subsequently, a stronger $\mathrm{H}_{2} \mathrm{O}_{2}$ response was generated in the whole infected and adjacent cells in L658 at 48 hpi, while $\mathrm{H}_{2} \mathrm{O}_{2}$ faded gradually in L958 at 48 and $72 \mathrm{hpi}$ (Figure 2A,B). In addition, the percentage of interaction sites stained by DAB had no significant difference between L658 and L958 at 12 and 24 hpi, while that in L658 was significantly $(p<0.05)$ higher at both 6 and 48 hpi and lower at 72 hpi than that in L958 (Figure 2C). 


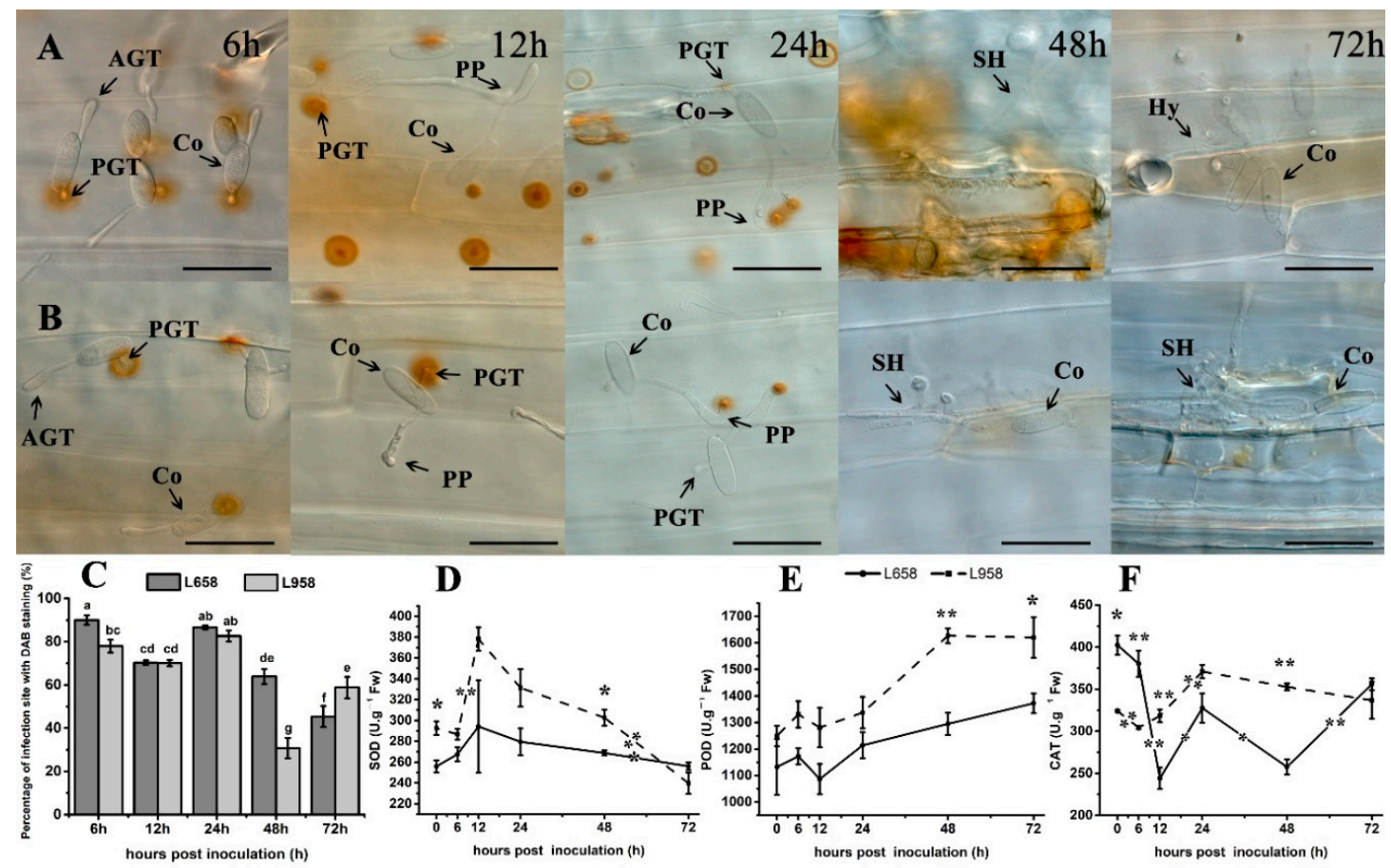

Figure 2. $\mathrm{H}_{2} \mathrm{O}_{2}$ accumulation revealed by 3 '-diaminobenzidine (DAB) staining at interaction sites in the resistant wheat line L658 and susceptible wheat line L958 after inoculation with Bgt and activity of antioxidant enzymes at various time points. $\mathrm{H}_{2} \mathrm{O}_{2}$ accumulation (reddish-brown) staining by DAB at interaction sites in L658 (A) and L958 (B) at various time points. AGT: appressorium germ tube; PGT, primary germ tube; PP: penetration peg; SH: secondary hyphae; Hy, hyphae; Co: conidia. The dark bar indicates $50 \mu \mathrm{m}$. (C) Dark grey and light grey bars represent the percentage of infection sites exhibiting $\mathrm{H}_{2} \mathrm{O}_{2}$ accumulation in L658 and L958, respectively, after inoculation with $\mathrm{Bgt}$ at various time points. Each point represents at least 100 infection sites of each of three leaf pieces, and the lowercase letter at the top of the bar chart represents statistically significant differences at $p<0.05$. Activities of SOD (D), POD (E), and CAT (F) at different inoculation time points in the two genotypes; the solid and dotted lines represent L658 and L958, respectively. The vertical bars represent the means \pm SEs. The asterisks represent significant differences as follows: ${ }^{* *} p<0.01$ and ${ }^{*} p<0.05$. The asterisk at the top of the line chart represents the difference between L658 and L958 at each time point. The asterisk on the trend line represents the difference between two adjacent time points for the same genotype.

To further determine the difference of $\mathrm{H}_{2} \mathrm{O}_{2}$ at the transcript level, we identified some DEGs related to $\mathrm{H}_{2} \mathrm{O}_{2}$ generation and $\mathrm{H}_{2} \mathrm{O}_{2}$ scavenging (Table 1). In L658, the expression of $\mathrm{H}_{2} \mathrm{O}_{2}$ generation-related DEGs, such as oxalate oxidase $(O X O)$ was upregulated, especially at $12 \mathrm{hpi}$, while the expression of many $\mathrm{H}_{2} \mathrm{O}_{2}$-scavenging DEGs, such as POD and CAT isozymes, was downregulated in L658 compared with L958 (Table 1). In L958, the expression of other $\mathrm{H}_{2} \mathrm{O}_{2}$ generation-related DEGs, including respiratory burst oxidase homologue protein $(R B O H)$, polyamine oxidase (POX), and amine oxidase $(A O X)$, were usually upregulated, while DEGs encoding POD and CAT were commonly upregulated in L958 compared with L658 (Table 1). This result indicated that although different DEGs regulated $\mathrm{H}_{2} \mathrm{O}_{2}$ generation in L658 and L958, the capacity to scavenge $\mathrm{H}_{2} \mathrm{O}_{2}$ was more seriously inhibited in L658 than L958. 
Table 1. List of DEGs involved in $\mathrm{H}_{2} \mathrm{O}_{2}$ production and scavenging between L658 and L958 at each time point.

\begin{tabular}{|c|c|c|c|c|c|c|c|}
\hline Gene ID & RO-S0 $^{\text {a }}$ & $\mathrm{R}^{\mathrm{C}-\mathrm{S} 6^{\mathrm{b}}}$ & R12-S12 c & R24-S24 ${ }^{d}$ & $\mathrm{R} 48-\mathrm{S} 48^{\mathrm{e}}$ & R72-S72 f & Functional Annotation G \\
\hline \multicolumn{8}{|c|}{$\mathrm{H}_{2} \mathrm{O}_{2}$-Producing-Related DEGs } \\
\hline TraesCS6A01G180600 & -6.446 & -7.180 & -6.906 & -10.076 & -7.352 & -9.351 & Respiratory burst oxidase homologue protein $\mathrm{E}$ \\
\hline TraesCS5B01G299000 & l & / & 1 & l & l & -2.425 & Respiratory burst oxidase homologue protein $C$ \\
\hline TraesCS5A01G527600 & / & / & / & / & / & -2.885 & Respiratory burst oxidase homologue protein $B$ \\
\hline TraesCS4B01G282700 & / & / & -3.409 & / & / & / & Primary amine oxidase \\
\hline TraesCS7D01G375700 & -3.550 & -3.876 & -2.744 & -3.351 & -5.309 & -6.213 & Polyamine oxidase \\
\hline TraesCS7A01G378800 & -4.452 & -4.832 & l & l & -5.345 & -6.612 & Polyamine oxidase \\
\hline TraesCS7B01G280700 & 2.374 & l & i & 1 & 2.694 & 3.339 & Polyamine oxidase \\
\hline TraesCS4A01G279300 & / & / & / & / & / & -6.283 & Oxalate oxidase GF-2.8 \\
\hline TraesCS4D01G032000 & 3.726 & I & 3.098 & l & I & I & Oxalate oxidase GF-2.8 \\
\hline TraesCS4B01G033300 & l & I & 2.727 & 1 & i & I & Oxalate oxidase GF-2.8 \\
\hline TraesCS4A01G279200 & l & l & 2.310 & I & I & l & Oxalate oxidase GF- 2.8 \\
\hline TraesCS4A01G279100 & / & / & 3.483 & / & / & / & Oxalate oxidase GF-2.8 \\
\hline TraesCS4A01G181800 & l & l & 3.865 & l & / & l & Oxalate oxidase GF-2.8 \\
\hline TraesCS4B01G033100 & 1 & l & l & l & l & -3.112 & Oxalate oxidase 2 \\
\hline TraesCS4D01G032200 & / & / & 2.298 & / & / & l & Oxalate oxidase 2 \\
\hline TraesCS4D01G032100 & -6.459 & l & 3.202 & l & 1 & l & Oxalate oxidase 2 \\
\hline \multicolumn{8}{|c|}{$\mathrm{H}_{2} \mathrm{O}_{2}$-Scavenging-Related DEGs } \\
\hline TraesCS6B01G278100 & / & / & / & -2.137 & / & / & glutathione peroxidase 6 , \\
\hline TraesCS1B01G115800 & 3.734 & 3.949 & 4.754 & 3.230 & 4.803 & 3.701 & Peroxidase N \\
\hline TraesCS1A01G104300 & -3.329 & / & / & / & -2.280 & -3.797 & Peroxidase A2 \\
\hline TraesCS6B01G063900 & / & / & / & / & I & -2.037 & Peroxidase 70 \\
\hline TraesCS6B01G063400 & 1 & I & l & I & I & -3.498 & Peroxidase 70 \\
\hline TraesCS6A01G047200 & 1 & 1 & 1 & 1 & 1 & -3.376 & Peroxidase 70 \\
\hline TraesCS6D01G303900 & l & l & -4.580 & 1 & -4.299 & l & Peroxidase 56 \\
\hline TraesCS6A01G324200 & I & I & -3.592 & I & I & I & Peroxidase 56 \\
\hline TraesCS1B01G115900 & -4.877 & -3.536 & -2.526 & -2.277 & -2.918 & -4.076 & Peroxidase 54 \\
\hline TraesCS1D01G096400 & -2.815 & I & I & l & -2.264 & -3.499 & Peroxidase 54 \\
\hline TraesCS7B01G132400 & / & 4.140 & / & / & l & 2.170 & Peroxidase 5 \\
\hline TraesCS1B01G096900 & l & / & -2.658 & 1 & 1 & -3.204 & Peroxidase 5 \\
\hline TraesCS1A01G079400 & 1 & I & -2.630 & I & I & I & Peroxidase 5 \\
\hline TraesCS4A01G196000 & 1 & 1 & -2.166 & 1 & 1 & i & Peroxidase 4 \\
\hline TraesCS5D01G144300 & I & I & / & 1 & 1 & -2.114 & Peroxidase 4 \\
\hline
\end{tabular}


Table 1. Cont

\begin{tabular}{|c|c|c|c|c|c|c|c|}
\hline Gene ID & $\mathrm{RO}^{\mathrm{S} \mathrm{SO}^{\mathrm{a}}}$ & $\mathrm{R}^{\mathrm{N}-\mathrm{S} 6^{\mathrm{b}}}$ & $\mathrm{R}_{12-S 12}{ }^{\mathrm{c}}$ & R24-S24 d & R48-S48 e & R72-S72 f & Functional Annotation G \\
\hline TraesCS5B01G147200 & / & / & / & / & I & -2.496 & Peroxidase 4 \\
\hline TraesCS2B01G098100 & / & / & / & 2.053 & / & l & Peroxidase 21 \\
\hline TraesCS3A01G297200 & 3.631 & i & i & / & 1 & i & Peroxidase 2 \\
\hline TraesCS2B01G124600 & l & -7.661 & / & / & / & / & Peroxidase 2 \\
\hline TraesCS3A01G297100 & 1 & 1 & 1 & 1 & 1 & -4.351 & Peroxidase 2 \\
\hline TraesCS2D01G584600 & -2.622 & / & / & / & i & 1 & Peroxidase 12 \\
\hline TraesCS2D01G583200 & / & / & 2.692 & / & / & I & Peroxidase 12 \\
\hline TraesCS2A01G573900 & 1 & 1 & / & / & 3.487 & / & Peroxidase 12 \\
\hline TraesCS2B01G125200 & / & 1 & 7.952 & 1 & I & / & Peroxidase 1 \\
\hline TraesCS2B01G125100 & / & / & / & / & 10.195 & l & Peroxidase 1 \\
\hline TraesCS2D01G107900 & 1 & -7.959 & 1 & 1 & / & 1 & Peroxidase \\
\hline TraesCS2B01G125300 & / & / & / & / & / & -7.743 & Peroxidase \\
\hline TraesCS4A01G106300 & -2.428 & -2.317 & 1 & / & / & -2.335 & L-ascorbate peroxidase 1 \\
\hline TraesCS6A01G118300 & -2.666 & 1 & / & -2.721 & -3.727 & -2.990 & Cationic peroxidase 1 \\
\hline TraesCS6A01G041700 & -4.483 & -4.691 & -3.521 & -5.265 & -4.937 & -5.815 & Catalase isozyme 2 \\
\hline
\end{tabular}

a, b, c, d, e, f: Log(fold-change) values of DEGs in L658 (R) compared with L958 (S) at 0, 6, 12, 24, 48, and 72 hpi ${ }^{\mathrm{G}}$ : Putative protein function predicted based on the Swiss-Prot database. 
The antioxidant enzyme activities further confirmed the transcriptome data. The results showed that although the activity of SOD and POD had no significant change in L658 (Figure 2D,E), CAT activity was sharply decreased from 6 to $12 \mathrm{hpi}(p<0.01)$ and from 24 to $48 \mathrm{hpi}(p<0.05)$ (Figure 2F). In L958, the activity of SOD significantly increased from 6 to $12 \mathrm{hpi}$ while the CAT activity also significantly increased from 12 to $24 \mathrm{hpi}$ (Figure 2F). In contrast, the CAT activity in L958 was significantly higher $(p<0.01)$ than that in $\mathrm{L} 658$ at 12 and 48 hpi (Figure 2F). Therefore, the inhibition of $\mathrm{H}_{2} \mathrm{O}_{2}$ scavenging-related genes and enzyme activities in L658 likely caused a more abundant accumulation of $\mathrm{H}_{2} \mathrm{O}_{2}$ than in L958.

\subsection{Changes in Photosynthesis and Photosynthesis-Related Genes in Response to Bgt}

Photosynthesis is not only the main generator of $\mathrm{H}_{2} \mathrm{O}_{2}$, but also regarded as a plant defence component [13]. To investigate the influence of $B g t$ in photosynthesis, we identified a large number of photosynthesis-related DEGs, most of which encoded chlorophyll a/b-binding proteins (Cab), proteins in reaction centres, ATP synthase (ATPase), ribulose bisphosphate carboxylase small chain/large chain (RbcS/L) and Rubisco activase (RCA) (Figure 3A). Interestingly, we found that almost all of the photosynthesis-related DEGs were downregulated in L658 compared with L958, and 54 (98\%) out of 55 and 75 (96\%) out of 78 photosynthesis-related DEGs were downregulated in L658 at 12 and 48 hpi, respectively (Figure 3B, Table S3). Furthermore, 41 and 98 DEGs were also downregulated in L658 at $12 \mathrm{hpi}$ and 48 hpi compared with $0 \mathrm{hpi}$, respectively, and 45 DEGs were also downregulated at $12 \mathrm{hpi}$ compared with 6 hpi in L658 (Figure 3C, Table S4). On the contrary, only eight photosynthesis-related DEGs were downregulated in L958 at both 24 and 72 hpi compared with 0 hpi, and 25 DEGs were downregulated at 24 hpi compared with 12 hpi (Figure 3C, Table S4). This result indicated that the expression of photosynthesis-related genes in L658 was more seriously inhibited compared with that in L958, which could lead to the disruption of photosynthesis. 
1

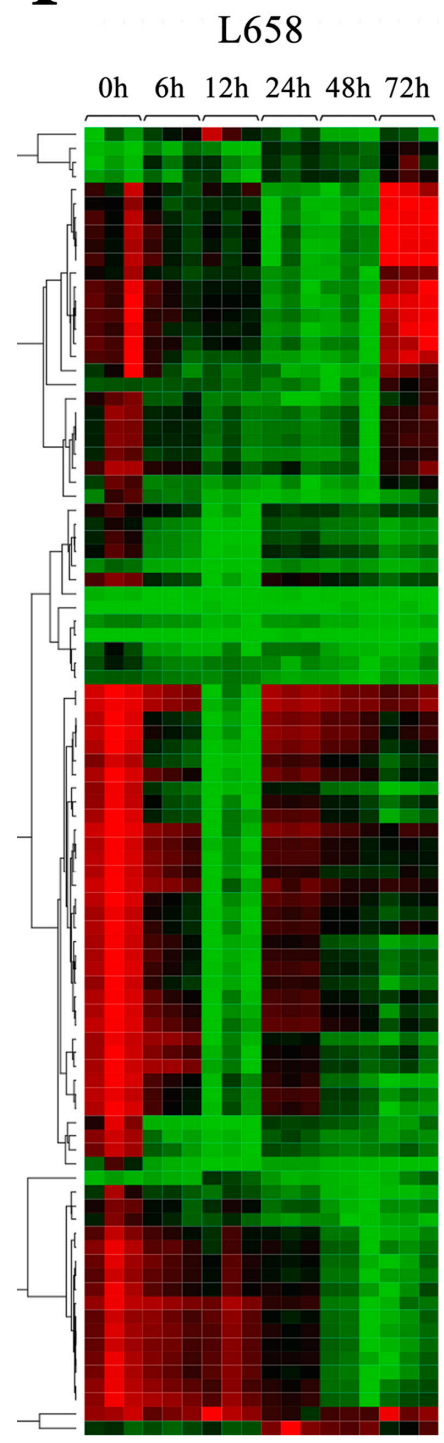

L958

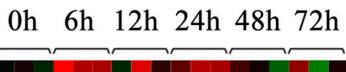$$
\text { coso }
$$
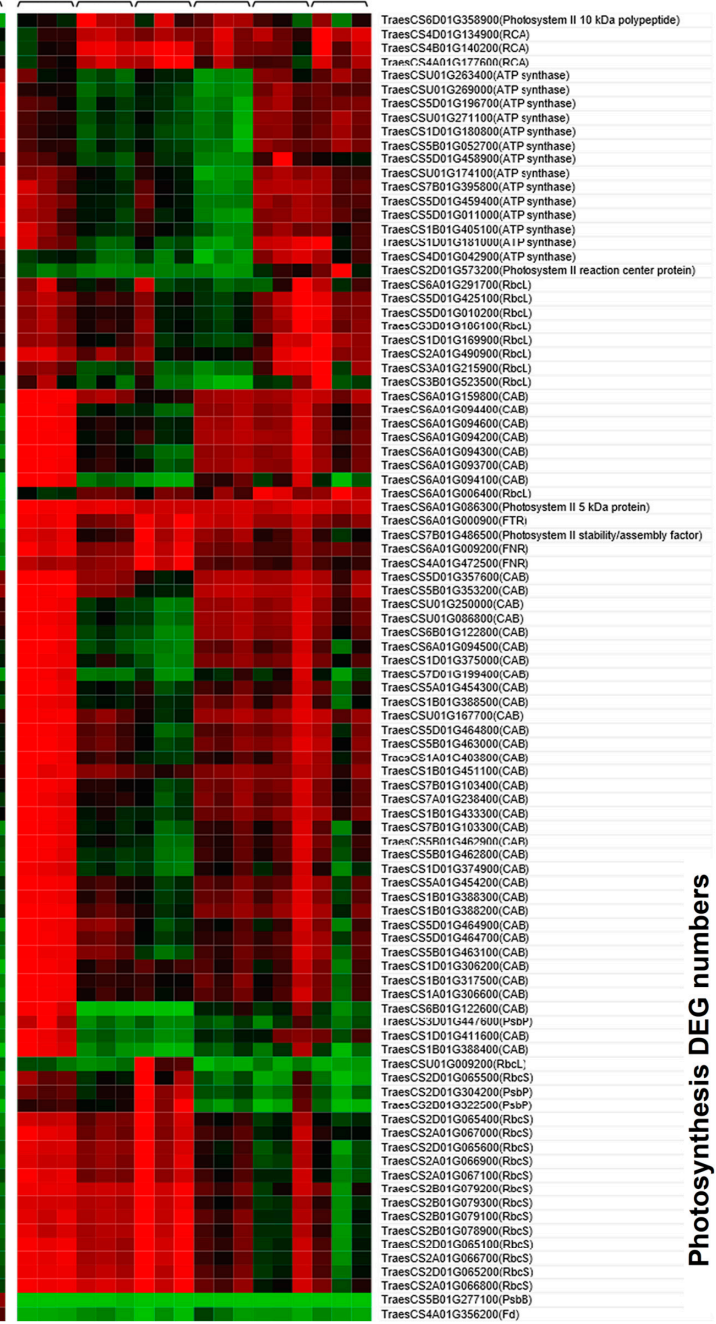

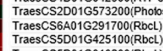

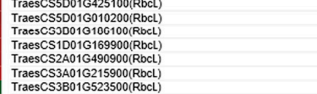

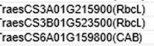

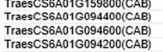

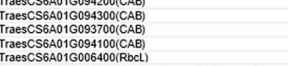

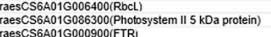

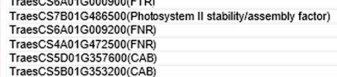

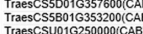

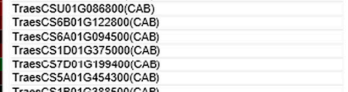

B
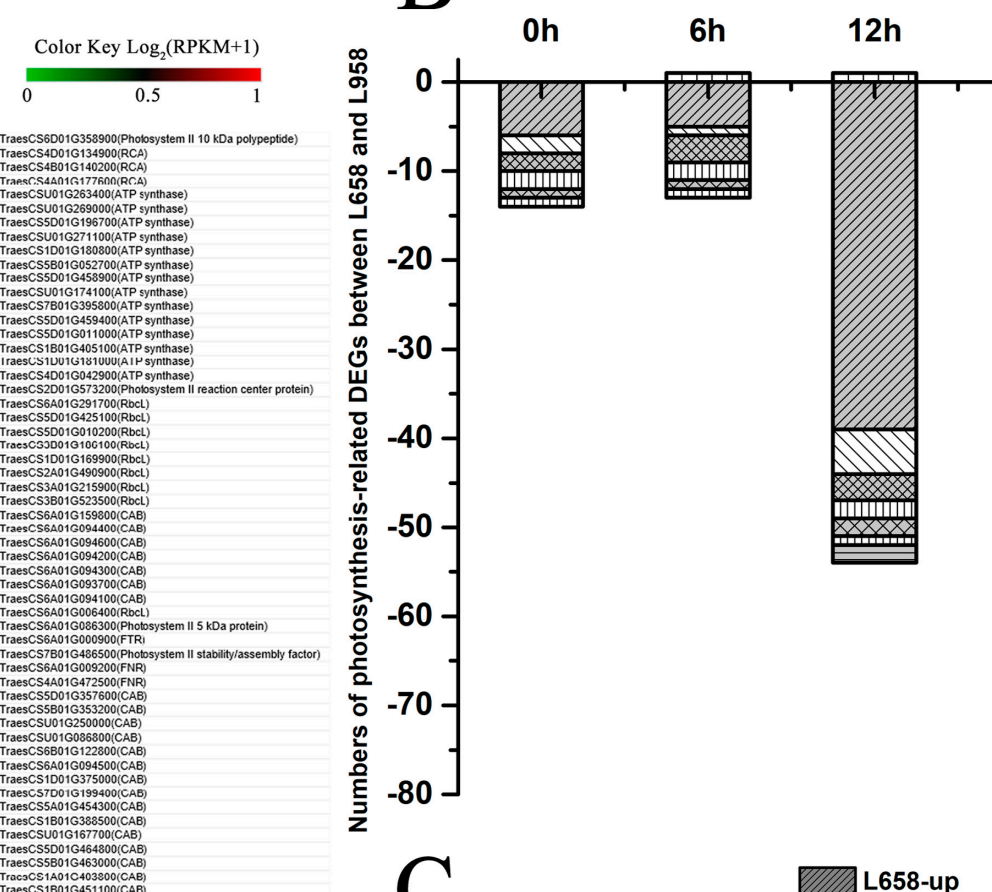

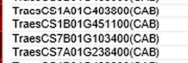

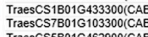

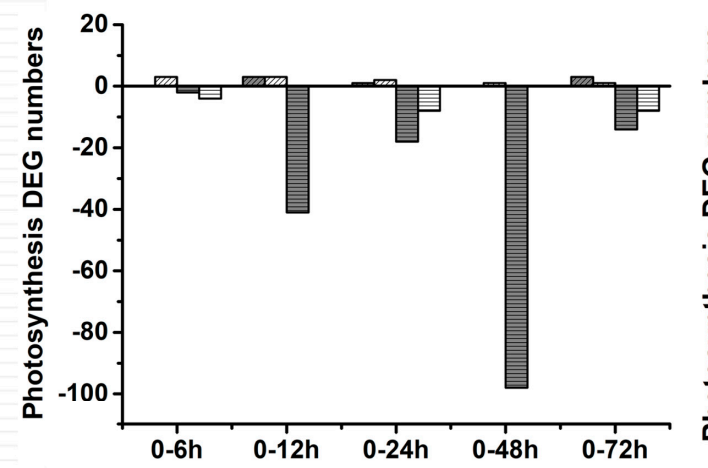

Figure 3. Number of DEGs and expression patterns of photosynthesis-related genes. (A) Different expression patterns of photosynthesis-related DEGs in L658 and L958 at various time points on the basis of $\log 2$ of RPKM values +1 ; the green colour represents low expression levels, and the red colour represents high expression levels. (B) Number of different photosynthesis-related DEGs between L658 and L958 at various time points. The negative numbers and positive numbers represent downregulated and upregulated DEGs in L658 compared with L958, respectively. ATPase: ATP synthase; FTR: ferredoxin-thioredoxin reductase; Fd: ferredoxin; FNR: ferredoxin: $\mathrm{NADP}^{+}$oxidoreductase; RCA: Rubisco activase; RbcS/L: ribulose bisphosphate carboxylase small chain/large chain; Cab: chlorophyll a/b-binding protein. (C) Number of photosynthesis-related DEGs in L658 and L958 at various inoculation time points compared with $0 \mathrm{~h}$ (left) and between two adjacent time points (right).

To further confirm the photosynthesis-related transcriptome data, we detected the photosynthetic parameters. As shown in Figure 4, the net photosynthetic rate (Pn) of L658 decreased from 0 hour (without inoculation) to $12 \mathrm{hpi}$ and from 48 to $72 \mathrm{hpi}$ (Figure 4A) and stomatal conductance (Gs) exhibited a reduction from 0 to $12 \mathrm{hpi}$ and an increase from 12 to $72 \mathrm{hpi}$ (Figure $4 \mathrm{~B}$ ). Compared with 
Pn, the intercellular $\mathrm{CO}_{2}$ concentration (Ci) of L658 increased significantly $(p<0.01)$ from 6 to $12 \mathrm{hpi}$ and from 24 to 72 hpi (Figure 4C). The opposite change trend of Pn and Ci in L658 indicated that non-stomatal limitation, such as the inhibition of photosynthesis-related gene expression, was the main reason for the decline of Pn. However, the Pn, Gs, and Ci of L958 showed similar change trends, with a decrease from 0 to $12 \mathrm{hpi}$ and from 48 to $72 \mathrm{hpi}$ (Figure $4 \mathrm{~A}-\mathrm{C}$ ), which indicated that the Pn of L958 decreased under stomatal limitation.
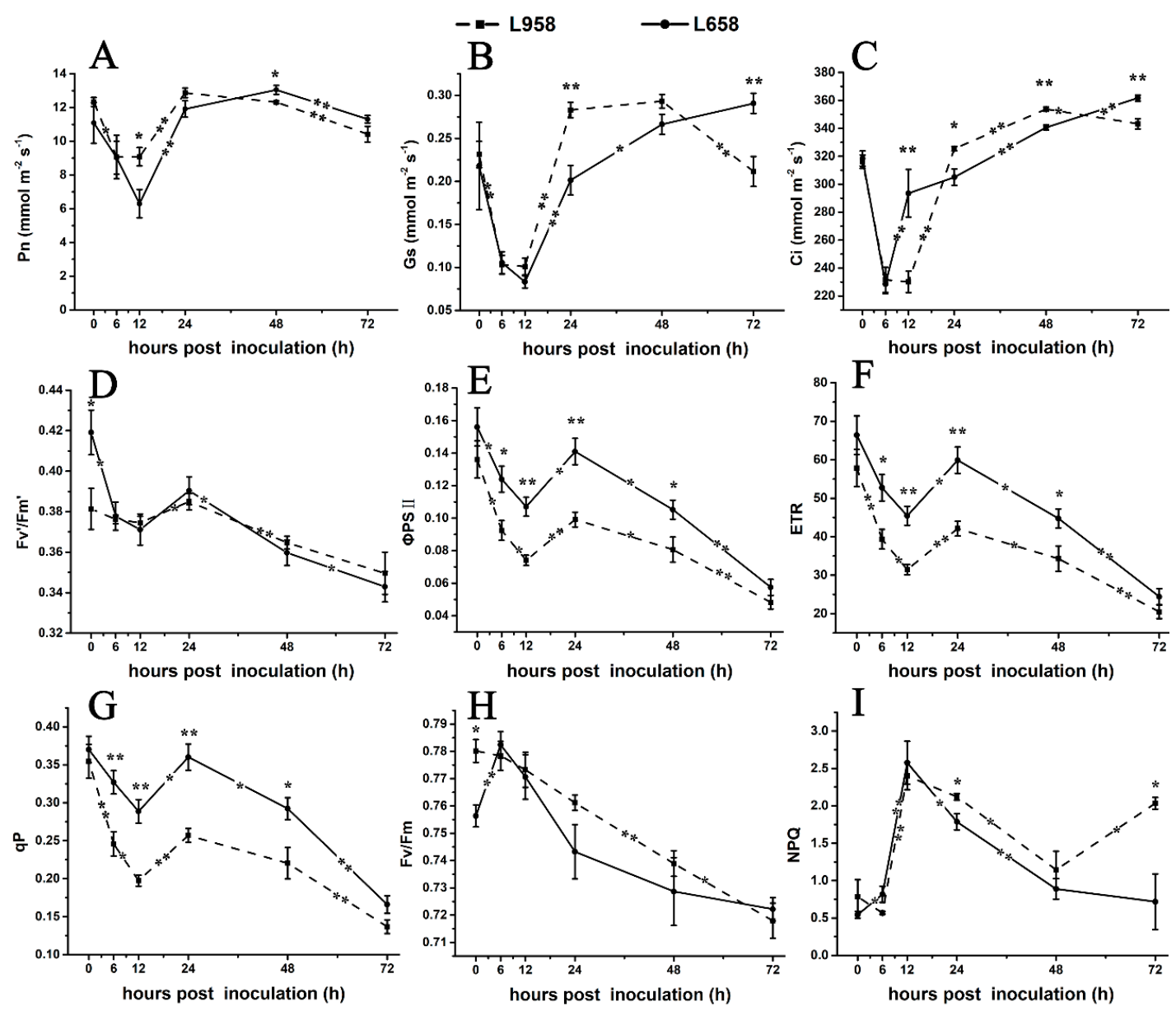

Figure 4. Changes in photosynthesis parameters and chlorophyll florescence parameters in L658 and L958. The solid and dotted lines represent different trends in the Pn (A), Gs (B), Ci (C), Fv'/Fm' (D), ФPSII (E), ETR (F), qP (G), Fv/Fm (H), and NPQ (I) in L658 and L958. The meanings of the symbols are the same as those in Figure 1. The asterisks represent significant differences as follows: ${ }^{* *} p<0.01$ and * $p<0.05$. The asterisk at the top of the line chart represents the difference between L658 and L958 at each time point. The asterisk on the trend line represents the difference between two adjacent time points for the same genotype.

Furthermore, we used chlorophyll fluorescence to evaluate changes in PSII. In L658, the efficiency of excitation capture by open PSII reaction centres $\left(\mathrm{Fv}^{\prime} / \mathrm{Fm}^{\prime}\right)$, actual photochemical efficiency of PSII ( $\left.\Phi_{\text {PSII }}\right)$, electron transport rate (ETR), and coefficient of photochemical chlorophyll fluorescence quenching (qP) decreased from 0 to $12 \mathrm{hpi}$ and from 24 to $72 \mathrm{hpi}$ (Figure $4 \mathrm{D}-\mathrm{G}$ ), and the maximal photochemical efficiency of PSII in dark-adapted leaves (Fv/Fm) increased from 0 to 6 hpi and then decreased to 72 hpi (Figure $4 \mathrm{H}$ ). Although the change tendency of $\mathrm{Fv}^{\prime} / \mathrm{Fm}^{\prime}, \Phi_{\text {PSII }}$, ETR and qP of L958 was similar to that of L658, the $\Phi_{\mathrm{PSII}}$, ETR and qP of L958 were inhibited more strongly than those of L658 (Figure 4D-G). Interestingly, non-photochemical quenching (NPQ) significantly $(p<0.05)$ increased from 0 to $12 \mathrm{hpi}$ and decreased from 12 to $72 \mathrm{hpi}$ in L658, while it decreased from 0 to $6 \mathrm{hpi}$ and increased from 48 to 72 hpi in L958 (Figure 4I). These data indicated that although the electron 
transport chain was blocked in both L658 and L958, the different changes of NPQ from 48 to 72 hpi may cause the differences in $\mathrm{H}_{2} \mathrm{O}_{2}$ accumulation at 48 and 72 hpi between L658 and L958.

\subsection{Identification of DEGs Related to Phytohormones and PR Proteins}

To understand the difference in hormone regulation between L658 and L958, we identified some phytohormone DEGs. The DEGs involved in SA synthesis, such as salicylic acid-binding protein (SABP) and isochorismate synthase (ICS), were downregulated in L658. However, NPR1, which is a downstream key regulator of SA, was upregulated in L658 at all time points (Table 2, Figure S1). In contrast, the DEGs involved in JA/ET pathways, such as the JA biosynthesis-related DEGs encoding lipoxygenase (LOX) and allene oxide synthase (AOS), and nearly all ET-related DEGs, including ethylene-responsive transcription factor $(E R F)$, ethylene insensitive $(E I N)$, 1-aminocyclopropane-1-carboxylate synthase $(A C S)$, and 1-aminocyclopropane-1-carboxylate oxidase (ACO), were globally downregulated in L658, especially at 72 hpi (Table 2, Figure S1). On the contrary, the expression of NPR1 was inhibited in L958, whereas JA/ET-related genes were highly expressed (Table 2, Figure S1). The results of the qRT-PCR analysis further confirmed that the expression of NPR1 and EBF1 in L658 was greater than that in L958 (Figure 5A,B), and the expression of LOX was lower in L658 than L958 (Figure 5C). These results showed that the SA pathway was activated and the JA/ET pathways were supressed in L658, while the JA pathway was overactivated in L958. 
Table 2. List of DEGs involved in hormone pathways between L658 and L958 at each time point.

\begin{tabular}{|c|c|c|c|c|c|c|c|}
\hline Gene ID & R0-S0 ${ }^{a}$ & $\mathrm{R}-\mathrm{S} 6^{\mathrm{b}}$ & ${\mathrm{R} 12-\mathrm{S} 12^{\mathrm{c}}}$ & R24-S24 ${ }^{\text {d }}$ & R48-S48 ${ }^{\mathrm{e}}$ & R72-S72 ${ }^{\mathrm{f}}$ & Functional Annotation $\mathrm{G}$ \\
\hline \multicolumn{8}{|c|}{ SA Pathway-Related DEGs } \\
\hline TraesCS3B01G354100 & / & / & -3.145 & / & / & / & Salicylic acid-binding protein 2 \\
\hline TraesCS3A01G325300 & 1 & 1 & -2.796 & 1 & / & / & Salicylic acid-binding protein 2 \\
\hline TraesCS3A01G325200 & / & / & -3.361 & I & / & / & Salicylic acid-binding protein 2 \\
\hline TraesCS5D01G196200 & / & / & -2.201 & / & / & / & Isochorismate synthase 2 , chloroplastic \\
\hline TraesCS7A01G021800 & 11.409 & 7.903 & 12.994 & 8.314 & 12.449 & 12.138 & Regulatory protein NPR1 \\
\hline \multicolumn{8}{|c|}{ JA Pathway-Related DEGs } \\
\hline TraesCS2A01G525500 & / & / & / & / & / & -3.867 & Seed linoleate 9S-lipoxygenase-3 \\
\hline TraesCS6A01G132500 & -7.376 & -7.356 & -5.173 & -7.744 & -8.013 & -12.116 & Putative linoleate 9S-lipoxygenase 3 \\
\hline TraesCS6A01G132200 & -13.320 & -9.317 & -10.259 & -8.741 & -14.0 & -15.902 & Putative linoleate 9S-lipoxygenase 3 \\
\hline TraesCS2D01G528500 & l & I & / & 1 & / & -3.547 & Probable linoleate 9S-lipoxygenase 5 \\
\hline TraesCS2B01G555400 & 1 & -2.347 & -2.003 & / & -2.112 & -4.107 & Probable linoleate 9S-lipoxygenase 5 \\
\hline TraesCS6A01G181200 & -9.490 & -10.091 & -10.025 & -9.787 & -9.954 & -9.287 & Probable linoleate 9S-lipoxygenase 4 \\
\hline TraesCS6B01G193400 & / & / & / & -2.024 & l & -2.136 & Lipoxygenase 2.3, chloroplastic \\
\hline TraesCS6A01G166000 & -2.911 & -3.863 & -2.692 & -2.986 & -3.050 & -3.241 & Lipoxygenase 2.3 , chloroplastic \\
\hline TraesCS5D01G013400 & 1 & -3.160 & 1 & 1 & 1 & -4.632 & Lipoxygenase 2.1 , chloroplastic \\
\hline TraesCS5B01G006500 & / & / & / & / & / & -4.578 & Lipoxygenase 2.1 , chloroplastic \\
\hline TraesCS5A01G007900 & / & -3.314 & / & / & / & -4.997 & Lipoxygenase 2.1 , chloroplastic \\
\hline TraesCS4D01G035200 & / & 1 & / & i & / & -2.177 & Linoleate 9S-lipoxygenase 1 \\
\hline TraesCS4B01G037900 & l & / & l & / & / & -2.780 & Linoleate 9S-lipoxygenase 1 \\
\hline TraesCS4B01G037700 & / & 1 & 1 & 1 & 1 & -2.609 & Linoleate 9S-lipoxygenase 1 \\
\hline TraesCS4D01G238800 & / & / & / & / & / & -2.213 & Allene oxide synthase 2 \\
\hline TraesCS4D01G238700 & / & -5.215 & / & / & / & -6.243 & Allene oxide synthase 2 \\
\hline TraesCS4A01G061800 & / & -4.649 & / & / & / & -5.560 & Allene oxide synthase 2 \\
\hline TraesCS5D01G413200 & / & 1 & / & / & / & -2.171 & Allene oxide synthase 1 , chloroplastic \\
\hline \multicolumn{8}{|c|}{ ET Pathway-Related DEGs } \\
\hline TraesCS4D01G267500 & / & / & / & / & / & -2.162 & Ethylene-responsive transcription factor RAP2-4 \\
\hline TraesCS7D01G469200 & 2.464 & 3.022 & / & 2.404 & 3.519 & 3.703 & Ethylene-responsive transcription factor RAP2-13 \\
\hline TraesCS6D01G217800 & l & l & / & l & l & -2.935 & Ethylene-responsive transcription factor ERF053 \\
\hline TraesCS6B01G263800 & / & / & / & / & / & -2.383 & Ethylene-responsive transcription factor ERF053 \\
\hline TraesCS6A01G235100 & / & / & / & / & / & -2.041 & Ethylene-responsive transcription factor ERF053 \\
\hline TraesCS2A01G427700 & / & / & / & / & / & -2.389 & Ethylene-responsive transcription factor 7 \\
\hline TraesCS6A01G171900 & / & / & -2.474 & -2.076 & / & / & Ethylene-responsive transcription factor 3 \\
\hline TraesCS6B01G281000 & / & / & / & / & / & -4.540 & Ethylene-responsive transcription factor 2 \\
\hline TraesCS5D01G549200 & 2.379 & / & / & / & / & / & Ethylene-responsive transcription factor $1 \mathrm{~B}$ \\
\hline TraesCS2D01G391400 & l & / & / & / & 3.664 & / & Ethylene-responsive transcription factor $1 \mathrm{~B}$ \\
\hline
\end{tabular}


Table 2. Cont.

\begin{tabular}{|c|c|c|c|c|c|c|c|}
\hline Gene ID & R0-S0 a & R6-S6 ${ }^{b}$ & $\mathrm{R}_{12-S 12} \mathrm{c}$ & R24-S24 d & $\mathrm{R} 48-\mathrm{S} 48^{\mathrm{e}}$ & R72-S72 ${ }^{f}$ & Functional Annotation G \\
\hline TraesCS6D01G225500 & l & l & / & l & l & -4.057 & Ethylene-responsive transcription factor 1 \\
\hline TraesCS6A01G243300 & 1 & 1 & / & / & / & -2.602 & Ethylene-responsive transcription factor 1 \\
\hline TraesCS6A01G125700 & -10.243 & -10.428 & -11.097 & -9.384 & -8.635 & -8.945 & AP2-like ethylene-responsive transcription factor \\
\hline TraesCS5A01G547500 & -2.579 & -9.546 & -2.814 & -3.525 & l & -3.283 & Ethylene-insensitive protein 2 \\
\hline TraesCS6A01G181900 & -2.973 & -2.685 & -3.204 & -3.132 & -3.230 & -2.830 & EIN3-binding F-box protein 1 \\
\hline TraesCS2D01G394200 & / & / & / & / & / & -3.141 & 1-aminocyclopropane-1-carboxylate synthase \\
\hline TraesCS2B01G414800 & l & l & l & l & 2.471 & -2.460 & 1-aminocyclopropane-1-carboxylate synthase \\
\hline TraesCS4B01G005800 & -3.100 & -2.836 & -3.930 & -3.304 & -4.105 & -3.435 & 1-aminocyclopropane-1-carboxylate oxidase homologue 1 \\
\hline TraesCS4A01G499800 & 5.816 & 9.167 & 5.375 & l & 1 & l & 1-aminocyclopropane-1-carboxylate oxidase homologue 1 \\
\hline TraesCS6B01G356200 & / & / & / & / & 2.046 & / & 1-aminocyclopropane-1-carboxylate oxidase 3 \\
\hline TraesCS6B01G356000 & l & l & / & 2.029 & l & l & 1-aminocyclopropane-1-carboxylate oxidase 3 \\
\hline TraesCS5B01G232600 & l & l & -2.121 & I & l & I & 1-aminocyclopropane-1-carboxylate oxidase 1 \\
\hline TraesCS5B01G232700 & l & l & l & -2.167 & -2.657 & -2.075 & 1-aminocyclopropane-1-carboxylate oxidase 1 \\
\hline
\end{tabular}

a, b, c, d, e, f: Log(fold-change) values of DEGs in L658 (R) compared with L958 (S) at 0, 6, 12, 24, 48, and 72 hpi. G: Putative protein function predicted based on the Swiss-Prot database.

Table 3. List of DEGs encoding pathogenesis-related genes between L658 and L958 at each time point.

\begin{tabular}{|c|c|c|c|c|c|c|c|}
\hline Gene ID & R0-S0a & $\mathrm{R}^{2}-\mathrm{S6}^{\mathrm{b}}$ & ${\mathrm{R} 12-\mathrm{S} 12^{\mathrm{c}}}$ & R24-S24 ${ }^{\text {d }}$ & R48-S48 e & R72-S72 f & Functional Annotation $\mathrm{G}$ \\
\hline TraesCS5A01G336600 & / & / & -3.422 & / & / & / & Thaumatin-like protein 1a \\
\hline TraesCS4D01G227400 & / & / & 1 & 1 & 1 & -2.092 & Thaumatin-like protein 1 \\
\hline TraesCS4A01G070700 & 1 & 1 & 1 & 1 & 1 & -2.481 & Thaumatin-like protein 1 \\
\hline TraesCSU01G146600 & 7.428 & 1 & 6.732 & 1 & 1 & I & Thaumatin-like protein \\
\hline TraesCS6B01G473800 & 8.349 & 5.325 & 10.464 & l & l & / & Thaumatin-like protein \\
\hline TraesCS6B01G157700 & 1 & 1 & -10.474 & 1 & 1 & 1 & Thaumatin-like protein \\
\hline TraesCS6A01G129400 & / & / & -9.800 & 1 & 1 & / & Thaumatin-like protein \\
\hline TraesCS5A01G018200 & 3.579 & 1 & 1 & 1 & 1 & -3.910 & Thaumatin-like protein \\
\hline TraesCS5A01G017900 & 6.417 & / & / & / & 1 & 1 & Thaumatin-like protein \\
\hline TraesCS2A01G110300 & 6.281 & / & I & / & / & / & Thaumatin-like protein \\
\hline TraesCS7D01G252400 & / & 4.006 & 1 & 5.578 & 6.710 & 9.868 & Pathogenesis-related protein 5 \\
\hline TraesCS5D01G446900 & 7.736 & / & / & / & / & / & Pathogenesis-related protein 1 \\
\hline TraesCS5D01G446800 & 8.967 & 1 & 1 & 1 & 1 & 1 & Pathogenesis-related protein 1 \\
\hline TraesCS5B01G442700 & 7.025 & 1 & 1 & 1 & 1 & 1 & Pathogenesis-related protein 1 \\
\hline TraesCS5B01G442600 & 8.469 & / & 1 & 1 & 1 & / & Pathogenesis-related protein 1 \\
\hline TraesCS5A01G439800 & 9.128 & / & 7.573 & / & / & 1 & Pathogenesis-related protein 1 \\
\hline TraesCS5A01G189200 & / & / & 1 & 3.043 & 3.487 & i & Pathogenesis-related protein 1 \\
\hline
\end{tabular}


Table 3. Cont

\begin{tabular}{|c|c|c|c|c|c|c|c|}
\hline Gene ID & $\mathrm{RO}^{-S 0}{ }^{\mathrm{a}}$ & $\mathrm{R}^{\mathrm{S}-\mathrm{S} 6^{\mathrm{b}}}$ & $\mathrm{R}^{2}-\mathrm{S} 12^{\mathrm{c}}$ & R24-S24 ${ }^{\text {d }}$ & R48-S48 e & R72-S72 ${ }^{f}$ & Functional Annotation G \\
\hline TraesCS6A01G184600 & -3.957 & -3.644 & -3.377 & -4.044 & -4.598 & -4.097 & Nuclear ribonuclease \\
\hline TraesCS2D01G260000 & / & I & -2.898 & / & / & / & Ribonuclease 3 \\
\hline TraesCS6D01G320200 & l & l & / & -2.215 & / & -2.929 & Ribonuclease 1 \\
\hline TraesCS6A01G339600 & / & / & / & / & / & -2.331 & Ribonuclease 1 \\
\hline TraesCS2B01G182900 & / & / & / & -4.933 & / & -5.114 & Ribonuclease 1 \\
\hline TraesCS2A01G157400 & / & I & I & / & l & -2.490 & Ribonuclease 1 \\
\hline TraesCS1D01G149800 & 1 & -2.714 & -3.982 & / & / & -2.658 & Ribonuclease 1 \\
\hline TraesCS1D01G149700 & / & -4.139 & -5.318 & / & -4.500 & -5.191 & Ribonuclease 1 \\
\hline TraesCS1B01G170200 & / & -4.257 & -6.333 & / & / & / & Ribonuclease 1 \\
\hline TraesCS1B01G170100 & -2.735 & -5.066 & -4.986 & -3.003 & -5.493 & -6.239 & Ribonuclease 1 \\
\hline TraesCS1A01G152800 & -3.828 & -4.337 & -6.606 & -2.809 & -3.895 & -4.556 & Ribonuclease 1 \\
\hline TraesCS1A01G152600 & -2.595 & -5.057 & -4.745 & -2.907 & -5.539 & -6.020 & Ribonuclease 1 \\
\hline TraesCS4B01G267300 & / & / & -2.348 & / & / & / & Non-specific lipid-transfer protein-like protein \\
\hline TraesCS4A01G038400 & / & l & l & l & / & -2.042 & Non-specific lipid-transfer protein-like protein \\
\hline TraesCSU01G251500 & -2.325 & -2.823 & -4.662 & -3.183 & -4.485 & -3.858 & Non-specific lipid-transfer protein 4.3 \\
\hline TraesCSU01G147100 & -2.496 & -2.880 & -4.956 & -3.222 & -4.536 & -3.531 & Non-specific lipid-transfer protein 4.3 \\
\hline TraesCSU01G057300 & 1 & / & -2.685 & / & / & / & Non-specific lipid-transfer protein 4.3 \\
\hline TraesCSU01G057200 & l & / & -2.781 & / & l & l & Non-specific lipid-transfer protein 4.3 \\
\hline TraesCS3B01G064100 & -2.204 & -2.562 & -4.634 & -2.799 & -3.872 & -2.701 & Non-specific lipid-transfer protein 4.3 \\
\hline TraesCS3B01G063700 & -2.223 & -2.301 & -4.238 & -2.537 & -3.851 & -2.788 & Non-specific lipid-transfer protein 4.3 \\
\hline TraesCS3B01G063100 & l & l & -3.290 & -2.240 & -3.665 & -2.777 & Non-specific lipid-transfer protein 4.3 \\
\hline TraesCS3B01G063000 & / & l & -2.874 & / & -3.378 & -2.383 & Non-specific lipid-transfer protein 4.3 \\
\hline TraesCSU01G253500 & -2.544 & -3.492 & -4.653 & -3.085 & -3.277 & -3.503 & Non-specific lipid-transfer protein 4.1 \\
\hline TraesCSU01G237900 & -2.469 & -3.284 & -4.612 & -3.033 & -3.186 & -3.472 & Non-specific lipid-transfer protein 4.1 \\
\hline TraesCSU01G154200 & -2.469 & -3.291 & -4.524 & -2.990 & -3.226 & -3.472 & Non-specific lipid-transfer protein 4.1 \\
\hline TraesCSU01G147200 & -3.126 & -4.274 & -5.409 & -3.635 & -3.963 & -3.991 & Non-specific lipid-transfer protein 4.1 \\
\hline TraesCSU01G056900 & / & / & / & / & / & -3.454 & Non-specific lipid-transfer protein 4.1 \\
\hline TraesCSU01G056700 & / & l & -2.123 & l & / & / & Non-specific lipid-transfer protein 4.1 \\
\hline TraesCS3B01G064000 & -2.457 & -3.605 & -3.873 & -2.220 & -2.893 & -2.491 & Non-specific lipid-transfer protein 4.1 \\
\hline TraesCS3B01G063600 & / & -2.791 & -3.285 & / & -2.356 & -2.436 & Non-specific lipid-transfer protein 4.1 \\
\hline TraesCS3B01G063200 & / & l & -4.401 & -2.399 & -2.962 & -2.729 & Non-specific lipid-transfer protein 4.1 \\
\hline TraesCS2A01G477700 & l & l & -5.115 & I & / & / & Non-specific lipid-transfer protein \\
\hline TraesCS5A01G433100 & / & 9.147 & 5.006 & 4.132 & / & 4.231 & Non-specific lipid transfer protein GPI-anchored 2 \\
\hline TraesCS3D01G331400 & l & l & -2.567 & / & l & I & Non-specific lipid transfer protein GPI-anchored 2 \\
\hline
\end{tabular}

a, b, c, d, e, f: Log(fold-change) values of DEGs in L658 (R) compared with L958 (S) at 0, 6, 12, 24, 48, and 72 hpi. G: Putative protein function predicted based on the Swiss-Prot database. 

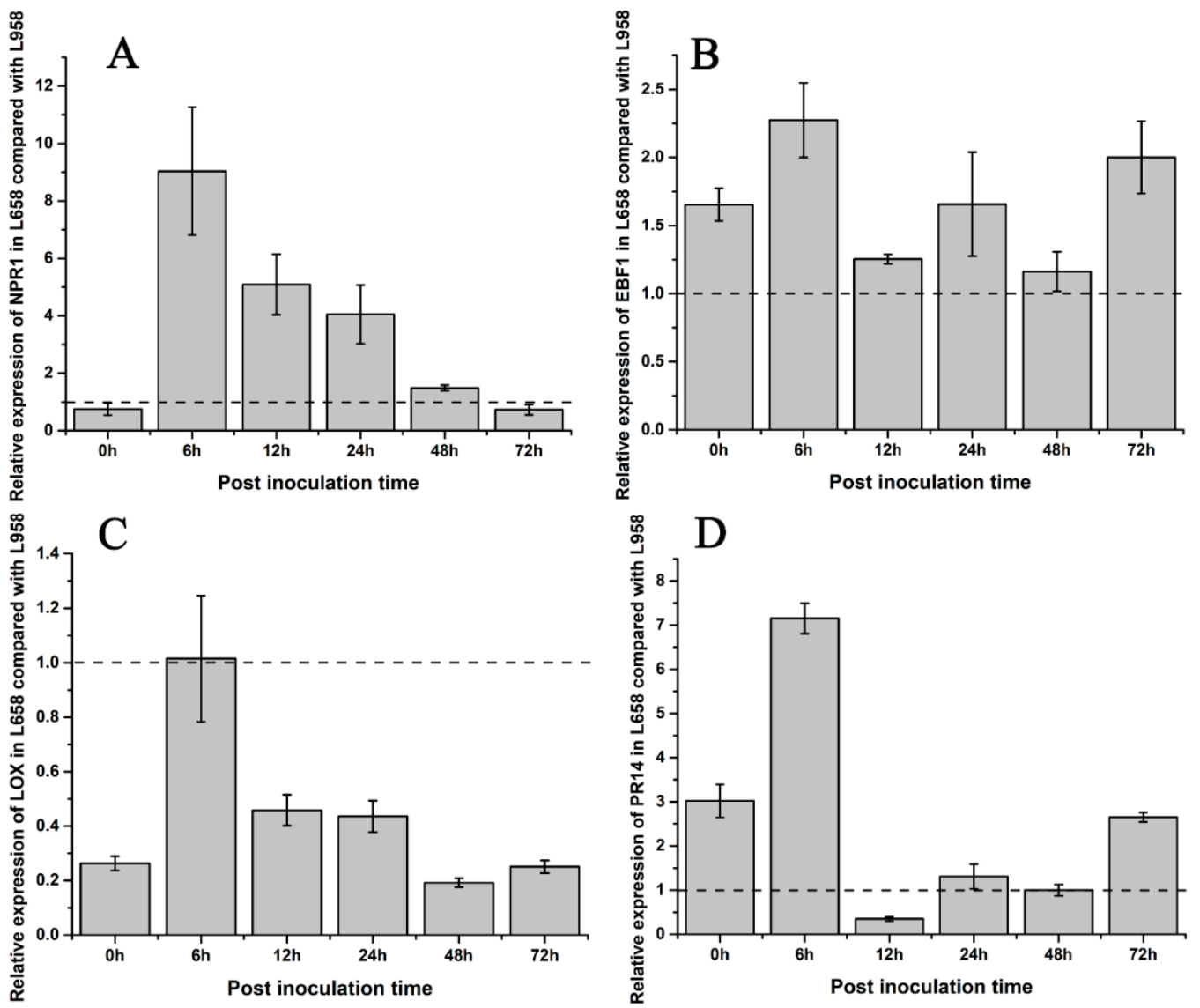

Figure 5. Fold change in the relative expression of defence-related genes detected by qRT-PCR in L658 compared with L958. The light grey bars represent the fold change in the relative expression of defence genes in L658 compared with L958. These genes included the following: (A) SA-related gene non-expressor of pathogenesis related genes 1, NPR1; (B) ethylene-related gene EIN3-binding F-box protein 1, EBF1; (C) JA-related gene lipoxygenase, LOX; and (D) pathogenesis-related protein 14, PR14. The dotted line means that the relative expression in L958 was set as 1 .

The dynamic expression patterns revealed that most of the DEGs encoding pathogenesis-related 1 (PR1) and pathogenesis-related 5 (PR5) were expressed at greater levels in L658, especially at 24 and 48 hpi, while nearly all DEGs encoding pathogenesis-related 10 (PR10) and pathogenesis-related 14 (PR14) were downregulated at all times in L658 (Table 3, Figure S2). However, both PR10 and PR14 exhibited opposite expression tendencies, with higher expression in L958 compared with L658 (Table 3, Figure S2). Furthermore, the results of the qRT-PCR analysis also confirmed that the relative expression of PR14 was lower in L658 than in L958 at 12 and 48 hpi (Figure 5D). Overall, the high expression of NPR1 in L658 activated the expression of PR1 and PR5, which further induced host cell death (Figure S3). However, the high expression of JA/ET-related genes and PR10 and PR14 in L958 may have suppressed the formation of HR (Figure S3).

\section{Discussion}

Powdery mildew is a leaf disease that causes substantial injuries to host photosynthesis, which results in the reduction of photosynthesis-related protein abundance and gene expression $[52,55,56]$. Previously, plant defence and photosynthesis were studied separately. However, a growing number of studies suggest that photosynthesis is highly related to plant immunity to pathogens $[13,14,19,42,43]$. Therefore, it is meaningful to investigate the cross-talk between photosynthesis and plant immunity. Dual RNA-seq is widely used to detect the gene expression in various pathosystems, thus providing an effective way to explain the molecular mechanism of plant-fungal interactions [57]. 
In addition, the measurement of photosynthesis-related parameters, including the net photosynthetic rate and chlorophyll fluorescence, is a very powerful method to monitor and quantify changes in photosynthesis $[58,59]$. In the present study, we characterized the expression profile of photosynthesis-related genes in resistant and susceptible wheat lines by comparing the wheat transcriptome after inoculation with $B g t$, at the same time we measured the photosynthesis-related parameters. In addition, we screened some $\mathrm{H}_{2} \mathrm{O}_{2}$ - and defence-related genes and determined cytological reactions to reveal the relationship between photosynthesis and immunity response.

3.1. Initial Stronger $\mathrm{H}_{2} \mathrm{O}_{2}$ Burst and Secondary Lasting $\mathrm{H}_{2} \mathrm{O}_{2}$ Burst Were Regulated by Antioxidant Enzyme Activities and $\mathrm{H}_{2} \mathrm{O}_{2}$-Related Genes and Occurred in Incompatible Reactions

ROS burst is one of the earliest immunity responses after the successful recognition of a pathogen [60]. In general, there are two distinct peaks of ROS burst induced during incompatible reactions: the first phase is often a low-amplitude and transient peak that is followed by a sustained burst of comparatively greater intensity that correlates with disease resistance; however, only the first transient burst of ROS is induced in compatible reactions [60-63]. In the present study, the first localized $\mathrm{H}_{2} \mathrm{O}_{2}$ burst was observed at 6 hpi, and the strength was stronger in L658 than L958 (Figure 2A-C). Subsequently, a stronger $\mathrm{H}_{2} \mathrm{O}_{2}$ accumulation generated around the whole infected and adjacent cells at 48 hpi in L658 while $\mathrm{H}_{2} \mathrm{O}_{2}$ faded gradually in L958 (Figure 2A-C). This result indicated that both the first stronger $\mathrm{H}_{2} \mathrm{O}_{2}$ burst and the second lasting $\mathrm{H}_{2} \mathrm{O}_{2}$ burst in $\mathrm{L} 658$ had an important role in the establishment of resistance.

To reveal the difference in $\mathrm{H}_{2} \mathrm{O}_{2}$ accumulation at the molecular level, we identified $\mathrm{H}_{2} \mathrm{O}_{2}$-related DEGs. Interestingly, the expression of the $\mathrm{H}_{2} \mathrm{O}_{2}$-generating DEG OXO was upregulated in L658 at $12 \mathrm{hpi} \mathrm{(Table} \mathrm{1).} \mathrm{In} \mathrm{previous} \mathrm{studies,} \mathrm{OXO} \mathrm{catalyses} \mathrm{the} \mathrm{degradation} \mathrm{of} \mathrm{oxalic} \mathrm{acid} \mathrm{secreted} \mathrm{by}$ fungi into $\mathrm{H}_{2} \mathrm{O}_{2}$ and is involved in $\mathrm{H}_{2} \mathrm{O}_{2}$ accumulation in the apoplasm during different cereal plant and fungal interactions $[16,64,65]$. However, powdery mildew does not secrete oxalic acid, thus, the primary role of $\mathrm{OXO}$ in cereals would seem to be the production of $\mathrm{H}_{2} \mathrm{O}_{2}$ to lignify cell walls against further fungal invasion $[65,66]$. Hence, DEGs encoding OXO in L658 may be involved in the first $\mathrm{H}_{2} \mathrm{O}_{2}$ burst to reinforce the cell wall or transmit defence signals. In addition to OXO, the expression of $\mathrm{H}_{2} \mathrm{O}_{2}$-scavenging DEGs in L658, including those encoding POD and CAT isozymes, emerged as being universally downregulated (Table 1), which corresponded with the inhibition of the POD and CAT enzyme activities in L658 (Figure 2E,F). The suppression of CAT enzyme activity promotes the increase of $\mathrm{H}_{2} \mathrm{O}_{2}$ concentration [29], and transgenic lines that overexpress CAT are more sensitive to pathogens because the capacity to remove $\mathrm{H}_{2} \mathrm{O}_{2}$ is over activated [67]. Furthermore, although the correlation between POD genes and plant defence is equivocal, PODs are generally considered to be $\mathrm{H}_{2} \mathrm{O}_{2}$-detoxifying enzymes that may indirectly modulate resistance by regulating $\mathrm{H}_{2} \mathrm{O}_{2}$ concentrations [68]. Taken together, the downregulation of $P O D$ and CAT gene expression in L658 was likely related to the suppression of enzyme activity, which further led to the increase of $\mathrm{H}_{2} \mathrm{O}_{2}$ accumulation. Moreover, the first $\mathrm{H}_{2} \mathrm{O}_{2}$ accumulation during the stage from 6 to 12 hpi was possibly involved in reinforcing the cell wall while the second lasting and stronger $\mathrm{H}_{2} \mathrm{O}_{2}$ accumulation from 48 to 72 hpi further induced the HR (Figure S3).

As for L958, three DEGs encoding $\mathrm{RBOH}$ were upregulated (Table 1). The $\mathrm{RBOH}$ family is reported to mediate the production of apoplastic ROS during the defence responses, however, various $\mathrm{RBOH}$ proteins might have different functions in disease resistance $[69,70]$. For example, silencing Rboh of N. benthamiana led to a suppression of HR and increased the susceptibility to Phytophthora infestans [71]. However, the Arabidopsis atrbohF mutant exhibited more resistance to Peronospora parasitica and increased the HR response [72]. Therefore, whether $\mathrm{RBOH}$ is involved in positive or negative resistance to Bgt in L958 needs to be further investigated, but DEGs encoding POD and CAT were clearly upregulated in L958 compared with L658, and the enzyme activities of SOD, POD, and CAT were also significantly higher in L958 compared with L658 (Table 1, Figure 2E,F). Therefore, although 
other DEGs likely regulated $\mathrm{H}_{2} \mathrm{O}_{2}$ generation, the capacity to scavenge $\mathrm{H}_{2} \mathrm{O}_{2}$ was enhanced in $\mathrm{L} 958$ compared with L658, which caused the first weaker $\mathrm{H}_{2} \mathrm{O}_{2}$ burst and failure of the second $\mathrm{H}_{2} \mathrm{O}_{2}$ burst.

\subsection{Global Downregulation of Photosynthesis-Related Genes Likely Disrupted Photosynthesis and Promoted the} Generation of $\mathrm{H}_{2} \mathrm{O}_{2}$

Generally, virulent or avirulent pathogen invasion often results in a decrease in photosynthesis to different extents, and the reduction in photosynthesis capability may represent a "hidden cost" of defence $[29,73]$. The plant transcriptome revealed that many photosynthesis-related genes are downregulated under biotic stress [29]. For example, photosynthesis and the expression of the photosynthesis-related transcripts, such as $C a b$ and $R b c S$, were reduced in barley-Blumeria graminis $\mathrm{f}$. sp. hordei (Bgh) incompatible interaction [74], and the downregulation of Rubisco and ATPase also occurred under other biotic stresses $[10,29,75]$. However, in some cases, such as in the incompatible interaction between Arabidopsis and P. syringae, the repression of photosynthesis was not correlated with the downregulation of $R b c S$ and $C a b$ transcripts [76], which may be related to the lack of participation of a majority of plant cells in the defence reaction, thus, the repression of $R b c S$ and $C a b$ cannot be detected in the whole leaves' RNA. In the present study, the downregulation of $C a b, R b c S$, and ATPase transcripts paralleled the decline in photosynthetic rate in L658, especially from 6 to $12 \mathrm{hpi}$ and from 48 to 72 hpi (Figures 3A and 4A). Meanwhile, the reduction of Pn in L658 was accompanied by the decrease of Gs and the increase of Ci (Figure 4B,C), which indicated that non-stomatal limitation led to the decrease of Pn in L658 [77,78], which was consistent with the above results. Taken together, the downregulation of photosynthesis-related DEGs in L658 likely switched off photosynthesis activity to strengthen the defence reaction. Inversely, only a small part of photosynthesis-related genes in L958 were downregulated (Figure 3C). Furthermore, the Pn, Gs, and Ci decreased consistently in L958 at 12 and 72 hpi (Figure 4A-C), which suggested that the decrease of Pn in L958 was primally controlled by stomatal limitation rather than to regulate immune response.

In addition, the expression of a DEG encoding Fd (TraesCS4A01G356200) was upregulated in L658 compared with L958 at 24 and 48 hpi (Figure 3A,B). In photosynthesis, Fd is a major element of photosynthesis-associated proteins that accept electrons from PSI and reduce $\mathrm{NADP}^{+}$by ferredoxin: $\mathrm{NADP}^{+}$oxidoreductase (FNR). In some plant-pathogen interactions, Fd has been suggested to participate in pathogen defence directly or to induce the production of ROS to mount the HR [29,34,38]. Therefore, it would be reasonable to assume that the upregulation of $F d$ in L658 may be involved in plant defence.

To further reveal the defence mechanism of photosynthesis, we monitored the status of PSII by detecting chlorophyll fluorescence indexes. In a previous study, Bgh infection led to a reduction of $\Phi_{\mathrm{PSII}}$, an increase of NPQ, and a reduction of Fv/Fm in barley [79]. In general, the increase of NPQ is a typical host response in plant-fungus interactions to protect plants when light energy absorption exceeds the capacity for light utilization, but the decrease in NPQ predisposes chloroplasts to the production of ROS, which might be a priming mechanism for chloroplast ROS signaling during later immune responses $[14,80,81]$. In our study, $\mathrm{Fv}^{\prime} / \mathrm{Fm}^{\prime}, \mathrm{Fv} / \mathrm{Fm}, \Phi_{\mathrm{PSII}}$, ETR, and qP significantly decreased in L658 at 12 and 72 hpi (Figure 4D-H). This response implied that photosynthetic electron transport was blocked, which could result in electron leakage in $\mathrm{L} 658$ for the generation of $\mathrm{H}_{2} \mathrm{O}_{2}$. Furthermore, the increase in NPQ in L658 at 12 hpi and the continuous decrease after 12 hpi may indicate that L658 needed photoprotection before $12 \mathrm{hpi}$ but tended to generate ROS at the late stage to induce the HR (Figure 4I). In L958, the $\Phi_{\text {PSII }}$, ETR, and qP were supressed more seriously than in L658 (Figure 4E-G), which may be due to damage to the chloroplasts after Bgt invasion. Interestingly, the NPQ of L958 increased at 72 hpi (Figure 4I), indicating that L958 did not activate the second ROS burst and thus was insufficient to induce the HR. 
3.3. Mutually Antagonistic Interactions between SA and JA/ET Are Involved in the Regulation of Defence Against Bgt by Regulating Different PR Genes Expression

The difference of $\mathrm{H}_{2} \mathrm{O}_{2}$ accumulation and photosynthesis might influence the different regulation of phytohormones, including SA, JA, and ET, after inoculation with Bgt. Generally, SA and JA interact antagonistically under different pathogen attacks and the SA bone fide receptor NPR1 acts as an important regulator to mediate cross-talk between SA and JA [82]. In addition, ET has positive effects on JA but may have positive or negative impacts on SA depending on the pathosystem $[83,84]$. Regarding the defences against biotrophic fungi, the SA signaling pathway is commonly activated and then directly regulates the conformation of NPR1 to induce the formation of SAR, the activation of PR1 and PR5 and to suppress the JA/ET signaling pathways [82,85,86]. In previous studies, the overexpression of NPR1 in tobacco and apple enhanced resistance to Botrytis cinereal and apple powdery mildew, respectively $[87,88]$. In a recent study, the repression of NPR1 in Brassica napus L. by RNAi significantly reduced resistance to Sclerotinia sclerotiorum, and silencing NPR1 inhibited SA defence response but enhanced the JA/ET defence response [89]. In the present study, although ICS expression was downregulated at $12 \mathrm{hpi}$, the transcript TraesCS7A01G021800 encoding NPR1 was upregulated in L658 (Table 2, Figure S1). Compared with SA, the expression of JA biosynthesis genes, including LOX and AOS, ET biosynthesis genes, including ACS and ACO, and ET-mediated signaling genes, such as ERF and EIN, were downregulated in L658, especially at 72 hpi (Table 2, Figure S1). Furthermore, the expression of PR1 and PR5 was upregulated in L658 (Table 3, Figure S2). Taken together, the downregulated expression of JA/ET-related genes indicated that JA/ET levels were also decreased, which could be attributed to increased SA levels in L658. The increased SA and the upregulated expression of NPR1, PR1, and PR5 likely induced the HR in L658.

However, in L958, JA/ET-related genes were strongly expressed (Table 2, Figure S1), which suggested that JA/ET levels increased in L958. Interestingly, the expression of the other two clusters of genes encoding PR10 and PR14 was largely upregulated in L958 as well (Table 3, Figure S2). It is reported that the expression of the PR10 gene is induced by JA and ABA [90]. Furthermore, silencing of PR10-like proteins in Medicago truncatula resulted in the reduced colonization of the oomycete Aphanomyces euteiches and induced the expression of PR5 [91]. In another research, a wheat orthologue of LTP, which is a member of the PR14 family, acted as a negative regulator to resist Puccinia striiformis f. sp. tritici (Pst), and the knockdown of this gene increased wheat resistance to Pst, which was accompanied by the accumulation of $\mathrm{H}_{2} \mathrm{O}_{2}$ and SA $[92,93]$. Therefore, the increase in JA/ET level and the high expression of PR10 and PR14 in L958 may act as negative regulators in the defence response to promote the establishment of susceptibility.

\section{Materials and Methods}

\subsection{Plant and Pathogen Materials}

The resistant wheat line L658 carrying Pm40 and its susceptible sister line L958 without Pm40 were used for comparative analyses by observations of cytological changes and determinations of physiological and biochemical indices. In addition, RNA-seq was performed for wheat plants after they were inoculated with $B g t$, as described previously [54]. The fungus was a single-spore isolate collected from a field at Wenjiang Farm, Chengdu, Sichuan Province, and propagated weekly on the highly susceptible wheat line CY20. The wheat plants were cultivated in a growth chamber (Microclima MC1750E, Snijders Scientific, Tilburg, Holland) at $18{ }^{\circ} \mathrm{C}$ and $80 \%$ relative humidity under a 16-h light/8-h dark photoperiod. Seven-day-old seedlings of L658 and L958 were inoculated with fresh Bgt spores at a density of 100-200 conidia/ $\mathrm{mm}^{2}$ by shaking infected leaf segments.

\subsection{Cytological Observations of $\mathrm{H}_{2} \mathrm{O}_{2}$ and Cell Death}

$\mathrm{H}_{2} \mathrm{O}_{2}$ accumulation was detected by the DAB (Sigma-Aldrich, Shanghai, China) staining method as described by Wang et al. [94]. The first leaves of L658 and L958 were harvested at 6, 12, 24, 48, and 
$72 \mathrm{hpi}$. The inoculated leaves were cut off and the end of cut leaves were immersed in $0.1 \%(w / v)$ DAB solution ( $\mathrm{pH} 3.8$ ) for $12 \mathrm{~h}$ to take up and react with the DAB fully. Cell death was detected by the trypan blue (Sigma-Aldrich, Shanghai, China) [53]. Leaf segments were immersed in $1 \%(w / v)$ TPB solution and then boiled for 2 min to stain the necrotic cells. Afterward, the leaf segments were decoloured in an ethanol-acetic acid $(1: 1, v / v)$ mixture until the chlorophyll was removed and then cleared in saturated chloral hydrate. The leaf segments were subsequently stored in $50 \%$ glycerol solution for examination and image collection via bright-field microscopy (Nikon Eclipse 80i, Nikon Corporation, Tokyo, Japan).

\subsection{Determination of Antioxidant Enzyme Activity}

A total of $0.2 \mathrm{~g}$ of fresh leaves was harvested at 6, 12, 24, 48, and $72 \mathrm{hpi}$ for preparation of the crude enzyme, and samples at $0 \mathrm{~h}$ (without inoculation) were used as controls. Each sample was detected with three biological replicates. The fresh leaves were immediately frozen in liquid nitrogen and then homogenized in $2 \mathrm{~mL}$ of $50 \mathrm{mM}$ pre-chilled phosphate buffer $(\mathrm{pH} 7.8)$ containing $1 \%(w / v)$ polyvinylpyrrolidone. The homogenate was then centrifuged at $12,000 \times g$ for $20 \mathrm{~min}$ at $4{ }^{\circ} \mathrm{C}$, after which the supernatant was used for determination of enzyme activities. The activities of SOD, CAT, and POD were measured at 560, 240, and $470 \mathrm{~nm}$, respectively, as described previously [51].

\subsection{Determination of Photosynthesis Indices}

The photosynthesis index data, including the Pn, Gs, and $\mathrm{Ci}$, were collected with a portable photosynthesis system (LI-6400-02B, LI-COR, Lincoln, NE, USA) as described previously [51], and the measurement conditions included a vapour pressure deficit (VPD) of $0.6 \mathrm{kPa}$ under an actinic light intensity of $1000 \mu \mathrm{mol} / \mathrm{m}^{2} / \mathrm{s}$ and an air temperature of $22^{\circ} \mathrm{C}$. The first measurements were performed before inoculation, and it was set as the controls $(0 \mathrm{~h})$. Subsequently, wheat leaves were inoculated with 100-200 conidia/mm² fresh spores at 9:00 am. After 6 h (15:00 p.m.), 12 h (21:00 p.m.), 24 h (9:00 a.m.), $48 \mathrm{~h}$ (9:00 a.m.), and $72 \mathrm{~h}$ (9:00 a.m.) post inoculation, the photosynthesis indices were collected. The measurements at six time points were performed under the light period of the growth chamber. The data of six independent replications of each genotype were collected by measuring the centre of the first leaf of the wheat plants. The means of these six replications were then analysed statistically.

\subsection{Measurements of Chlorophyll Fluorescence and Quantum Yields of PSII}

Chlorophyll fluorescence was measured with a portable photosynthesis system (LI-COR 6400XT, Lincoln, NE, USA) equipped with a leaf chamber fluorometer (LI-6400-40; LI-COR, Lincoln, NE, USA) as described previously [51]. Measurements were taken from the centre of the first leaves of L658 and L958 at 0 (without inoculation), 6, 12, 24, 48, and $72 \mathrm{hpi}$. Six plants of each genotype were checked independently at the different timepoints, and the average represented the phenotypic value for subsequent statistical analysis. The data of the $\mathrm{qP}$, maximum fluorescence in the light $\left(F m^{\prime}\right)$, variable chlorophyll fluorescence yield in the light $\left(F v^{\prime}\right)$, and $\Phi_{\mathrm{PSII}}$ were collected in the light. Furthermore, the maximum fluorescence $(F m)$ and variable chlorophyll fluorescence yield $(F v)$ were measured with a fluorescence meter after the plants were dark adapted for $30 \mathrm{~min}$.

\subsection{RNA Extraction, cDNA Library Construction, and RNA-Seq}

First leaves were randomly collected from L658 and L958 plants at 0, 6, 12, 24, 48, and 72 hpi, with each sample comprising three biological replicates. A total of 36 leaf samples were frozen in liquid nitrogen and then sent to a service company (Beijing Biomarker Technology Co, Ltd., Beijing, China) for RNA-seq. Briefly, the total RNA in wheat was extracted according to the TRIzol reagent method (Invitrogen Life Technologies, CA, USA). After the integrity and purity of the RNA was checked via an Agilent 2100 Bioanalyzer (Agilent Technologies, CA, USA) and a NanoDrop ND-1000 spectrophotometer (Thermo Scientific, DE, USA), a cDNA library was constructed by the use of a NEBNext Ultra RNA Library Prep Kit for Illumina (NEB, USA). Last, RNA-seq was performed on 
an Illumina HiSeq ${ }^{\mathrm{TM}} 2500$ platform in accordance with the 150-bp paired-end sequencing strategy. All the raw sequencing data have been submitted to the NCBI Sequence Read Archive (SRA), and the accession number is SRP117269 [54].

\subsection{Alignment of RNA-Seq Reads and Differential Gene Expression Analysis}

Reads that contained an adapter or a poly-N tail or those that were of low quality were removed from the raw reads. The filtered high-quality reads were then mapped to the IWGSC RefSeq v1.0 wheat genome reference (https://wheat-urgi.versailles.inra.fr/) by HISAT2 [95], the process of which allowed up to 2 base mismatches. All identified genes were functionally annotated via BLASTX of the non-redundant (NR) database and the Swiss-Prot protein database [96]. The expression level of the transcripts was subsequently calculated and normalized to an RPKM value by StringTie [97]. Furthermore, EdgeR [98] was applied to detect DEGs in pairwise comparisons with a threshold of a false discovery rate (FDR) $\leq 0.001$ and $\mid \log 2$ (fold change) $\mid \geq 2$.

\subsection{Reliable Analysis by $q R T-P C R$}

To confirm the reliability of the RNA-seq data, we randomly chose 12 expressed genes for qRT-PCR experiments. Transcript One-Step gDNA Removal and a cDNA Synthesis Supermix Kit (Transgen Biotech, Beijing, China) were used to synthesize cDNA for qRT-PCR. The primer sequences used were designed by NCBI Primer-BLAST and are listed in Additional Table S2. The reactions were conducted on a Thermal Cycler CFX96 Real-Time System (Bio-Rad Laboratories, Hercules, CA, USA) together with SYBR Green qPCR Master Mix (Omega, Beijing, China). The relative expression of the abovementioned 12 genes was calculated according to the $2^{-\Delta \Delta C t}$ method [99], with tubulin [100] and GAPDH [101] used as reference genes. The experiments were performed for three biological replicates, and each biological replicate involved three technical repeats.

\subsection{Statistical Analysis}

Significant differences in the mean physiological parameters, photosynthesis parameters and relative gene expression were determined by independent sample t-tests or Duncan's multiple range test via IBM Statistical Package for Social Science (SPSS) 19.0 software version 19.0 (SPSS Inc., Chicago, IL, USA). The data are presented as the mean values \pm standard error (SEs).

\section{Conclusions}

We investigated the differences in the physiological and biochemical status and in gene expression between L658 and L958 to reveal the mechanisms of Pm40-regulated resistance against Bgt, as shown in Figure 6. During the pre-penetration stage, the expression of genes encoding OXO was upregulated in L658 to generate $\mathrm{H}_{2} \mathrm{O}_{2}$. At the same time, the inhibition of photosynthesis caused by the downregulated expression of genes encoding $\mathrm{Cab}$, ATPase, and $\mathrm{RbcS} / \mathrm{L}$ generated $\mathrm{O}^{2-}$, which was dismutated into $\mathrm{H}_{2} \mathrm{O}_{2}$ by SOD. The suppression of POD and CAT further promoted the accumulation of $\mathrm{H}_{2} \mathrm{O}_{2}$ in L658. The first stage of $\mathrm{H}_{2} \mathrm{O}_{2}$ accumulation was at 6-12 hpi, and the $\mathrm{H}_{2} \mathrm{O}_{2}$ generated during this stage likely acted as a signaling molecule to provoke the second and relatively more intense burst of $\mathrm{H}_{2} \mathrm{O}_{2}$ at 48-72 hpi. The second $\mathrm{H}_{2} \mathrm{O}_{2}$ accumulation possibly enhanced SA levels by directly promoting the expression of SA-related genes or by indirectly inhibiting the expression of JA-/ET-related genes. Subsequently, SA likely activated the expression of NPR1, PR1, and PR5 and ultimately induced HR in L658. 


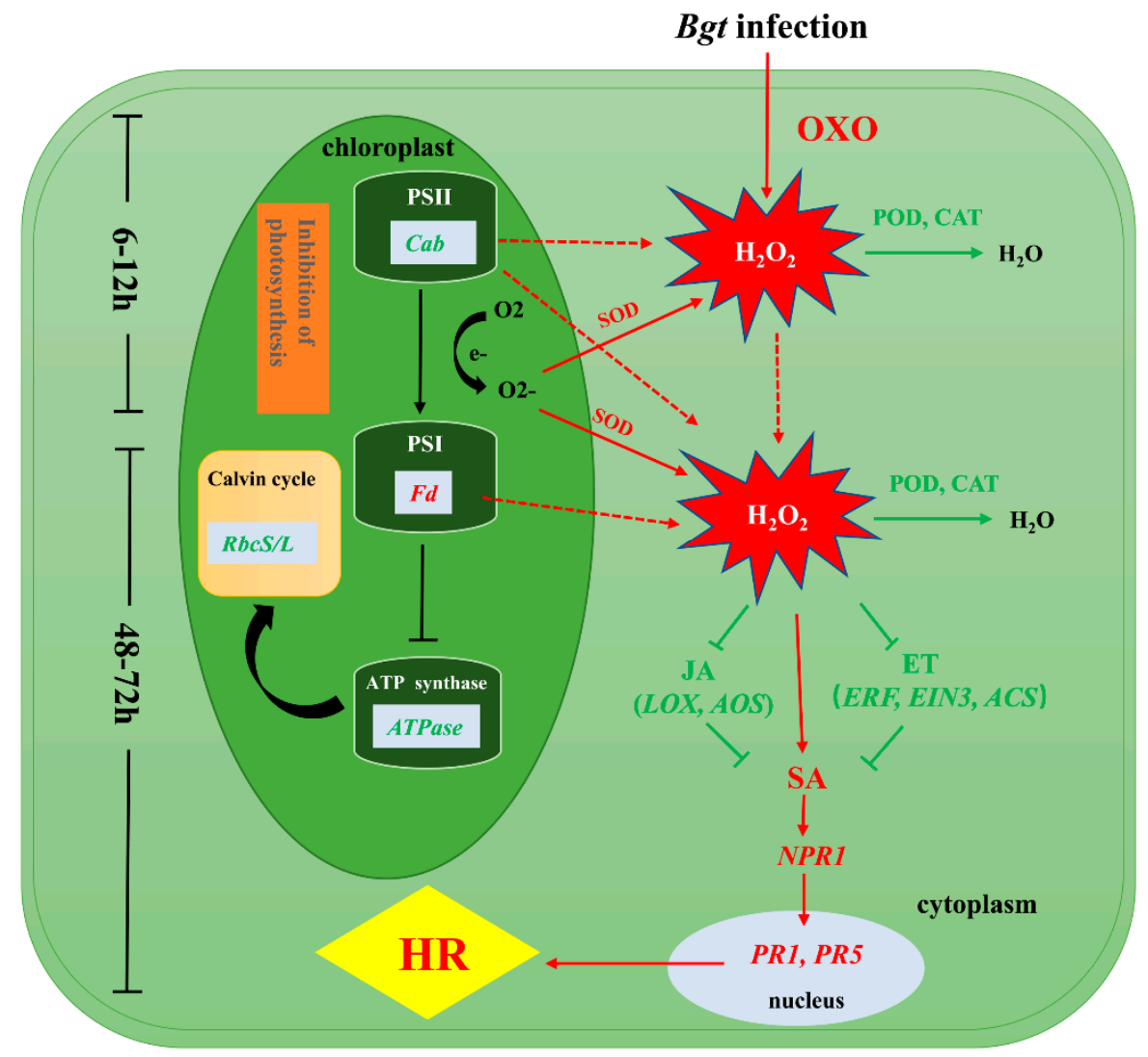

Figure 6. Presumptive schematic of the resistance mechanism synergistically regulated by photosynthesis, ROS and plant hormones in the Pm40-expressing wheat line L658. The green colour represents low expression levels, and the red colour represents high expression levels.

Supplementary Materials: Supplementary materials can be found at http://www.mdpi.com/1422-0067/21/16/ 5767/s1. Figure S1. Expression patterns of DEGs involved in the SA, JA, and ET pathways in L658 and L958. The green colour represents low expression levels, and the red colour represents high expression levels. Figure S2. Expression patterns of DEGs encoding different PR proteins in L658 and L958. The green colour represents low expression levels, and the red colour represents high expression levels. Figure S3. Localization of hypersensitive cell death at interaction sites in L658 and L958 after inoculation with Bgt and the changes in main photosynthesis parameters in the two genotypes. Necrosis (dark blue) staining by trypan blue at interaction sites in L658 (A) and L958 (B) at various time points. Table S1. Summary of RNA-seq data and read mapping. Table S2. List of forward and reverse primers designed for use in qRT-PCR. Table S3. Number of different photosynthesis-related DEGs between L658 and L958 at various time points. Table S4. Number of photosynthesis-related DEGs in L658 and L958 at various inoculation time points compared with $0 \mathrm{~h}$ and between two adjacent time points.

Author Contributions: M.Z., P.L., G.G., and X.C. designed the research; Y.H., Y.L., S.Z., X.Q., L.L., and H.Y. performed the research; Y.H., S.Z., F.T., and P.L. analysed the data; Y.H. and P.L. wrote the paper; M.Z. and P.L. acquired the financial support for the project leading to this publication. All authors have read and agreed to the published version of the manuscript.

Funding: This research was funded by the National Key R\&D Program of China (No. 2018YFD0200500).

Acknowledgments: We are grateful to Biomarker Technology Co., Ltd. (Beijing, China) for the technical assistance.

Conflicts of Interest: The authors declare no conflict of interest. The funders had no role in the design of the study; in the collection, analyses, or interpretation of data; in the writing of the manuscript, or in the decision to publish the results. 


\section{Abbreviations}

$\begin{array}{ll}\text { ABA } & \text { Abscisic Acid } \\ \text { ACO } & \text { 1-aminocyclopropane-1-carboxylate oxidase } \\ \text { ACS } & \text { 1-aminocyclopropane-1-carboxylate synthase } \\ \text { AOS } & \text { Allene Oxide Synthase } \\ \text { AOX } & \text { Amine Oxidase } \\ \text { APX } & \text { Peroxidase } \\ \text { ATPase } & \text { ATP synthase } \\ \text { Bgt } & \text { Blumeria graminis f. sp. tritici } \\ \text { Cabs } & \text { Chlorophyll a/b-binding proteins } \\ \text { CAT } & \text { Catalase } \\ \text { EIN } & \text { Ethylene insensitive } \\ \text { ERF } & \text { Ethylene-responsive transcription factor } \\ \text { ET } & \text { Ethylene } \\ \text { Fd-I } & \text { Ferredoxin-I } \\ \text { FNR } & \text { Ferredoxin: NADP+ oxidoreductase } \\ \text { ICS } & \text { Isochorismate Synthase } \\ \text { JA } & \text { Jasmonic Acid } \\ \text { LOX } & \text { Lipoxygenase } \\ \text { NPR1 } & \text { Non-expressor of Pathogenesis Related genes 1 } \\ \text { OXO } & \text { Oxalate Oxidase } \\ \text { PGT } & \text { Primary Germ Tube } \\ \text { POD } & \text { Peroxidase } \\ \text { POX } & \text { Polyamine Oxidase } \\ \text { PP } & \text { Penetration Peg } \\ \text { PR1 } & \text { Pathogenesis-related 1 } \\ \text { PR5 } & \text { Pathogenesis-related 5 } \\ \text { PR10 } & \text { Pathogenesis-related 10 } \\ \text { PR14 } & \text { Pathogenesis-related 14 } \\ \text { RbcS/L } & \text { Ribulose bisphosphate carboxylase small chain/large chain } \\ \text { RBOH } & \text { Respiratory Burst Oxidase Homologue protein } \\ \text { RCA } & \text { Rubisco Activase } \\ \text { ROS } & \text { Reactive Oxygen Species } \\ \text { SA } & \text { Salicylic Acid } \\ \text { SABP } & \text { Salicylic Acid-binding protein } \\ \text { SOD } & \text { Superoxide dismutase } \\ & \end{array}$

\section{References}

1. Pimentel, D. Diversification of biological control strategies in agriculture. Crop. Prot. 1991, 10, $243-253$. [CrossRef]

2. Pimentel, D. (Ed.) Biological Invasions: Economic and Environmental Costs of Alien Plant Animal and Microbe Species; CRC Press: Boca Raton, FL, USA, 2002; p. 384.

3. Chisholm, S.T.; Coaker, G.; Day, B.; Staskawicz, B.J. Host-microbe interactions: Shaping the evolution of the plant immune response. Cell 2006, 124, 803-814. [CrossRef] [PubMed]

4. Jones, J.D.; Dangl, J.L. The plant immune system. Nature 2006, 444, 323-329. [CrossRef] [PubMed]

5. Torres, M.A. ROS in biotic interactions. Physiol. Plantarum. 2010, 138, 414-429. [CrossRef]

6. Melotto, M.; Underwood, W.; He, S.Y. Role of stomata in plant innate immunity and foliar bacterial diseases. Annu. Rev. Phytopathol. 2008, 46, 101-122. [CrossRef]

7. Hardham, A.R.; Jones, D.A.; Takemoto, D. Cytoskeleton and cell wall function in penetration resistance. Curr. Opin. Plant Biol. 2007, 10, 342-348. [CrossRef]

8. Coll, N.S.; Epple, P.; Dangl, J.L. Programmed cell death in the plant immune system. Cell Death Differ. 2011, 18, 1247-1256. [CrossRef] 
9. Fu, Z.Q.; Dong, X. Systemic acquired resistance: Turning local infection into global defense. Annu. Rev. Plant Biol. 2013, 64, 839-863. [CrossRef]

10. Li, X.; Zhong, S.F.; Chen, W.Q.; Fatima, S.A.; Huang, Q.L.; Li, Q.; Tan, F.Q.; Luo, P.G. Transcriptome analysis identifies a $140 \mathrm{~kb}$ region of chromosome $3 \mathrm{~B}$ containing genes specific to Fusarium Head Blight resistance in wheat. Int. J. Mol. Sci. 2018, 19, 852. [CrossRef]

11. Herrera-Vásquez, A.; Salinas, P.; Holuigue, L. Salicylic acid and reactive oxygen species interplay in the transcriptional control of defense genes expression. Front. Plant Sci. 2015, 6, 171. [CrossRef] [PubMed]

12. Katagiri, F.; Kenichi, T. Understanding the plant immune system. Mol. Plant Microbe Interact. 2010, 23, 1531-1536. [CrossRef] [PubMed]

13. Kretschmer, M.; Damoo, D.; Djamei, A.; James, K. Chloroplasts and Plant Immunity: Where Are the Fungal Effectors? Pathogens 2020, 9, 19. [CrossRef]

14. Sowden, R.G.; Watson, S.J.; Jarvis, P. The role of chloroplasts in plant pathology. Essays Biochem. 2017, 62, 21-39.

15. Saxena, I.; Srikanth, S.; Chen, Z. Cross talk between $\mathrm{H}_{2} \mathrm{O}_{2}$ and interacting signal molecules under plant stress response. Front. Plant Sci. 2016, 7, 570. [CrossRef] [PubMed]

16. Sharma, P.; Jha, A.B.; Dubey, R.S.; Pessarakli, M. Reactive oxygen species oxidative damage and antioxidative defense mechanism in plants under stressful conditions. J. Bot. 2012, 2012, 217037. [CrossRef]

17. Asada, K. Production and scavenging of reactive oxygen species in chloroplasts and their functions. Plant Physiol. 2006, 141, 391-396. [CrossRef]

18. Apel, K.; Hirt, H. Reactive oxygen species: Metabolism oxidative stress and signal transduction. Annu. Rev. Plant Biol. 2004, 55, 373-399. [CrossRef]

19. Lu, Y.; Yao, J. Chloroplasts at the crossroad of photosynthesis pathogen infection and plant defense. Int. J. Mol. Sci. 2018, 19, 3900. [CrossRef]

20. Asada, K. The water-water cycle in chloroplasts: Scavenging of active oxygens and dissipation of excess photons. Annu. Rev. Plant Biol. 1999, 50, 601-639. [CrossRef]

21. Badger, M.R.; von Caemmerer, S.; Ruuska, S.; Nakano, H. Electron flow to oxygen in higher plants and algae: Rates and control of direct photoreduction (Mehler reaction) and rubisco oxygenase. Philos. T. Roy. Soc. B 2000, 355, 1433-1446. [CrossRef]

22. Sabater, B.; Martín, M. Hypothesis: Increase of the ratio singlet oxygen plus superoxide radical to hydrogen peroxide changes stress defense response to programmed leaf death. Front. Plant Sci. 2013, 4, 479. [CrossRef] [PubMed]

23. Mittler, R.; Vanderauwera, S.; Suzuki, N.; Miller, G.A.D.; Tognetti, V.B.; Vandepoele, K.; Gollery, M.; Shulaev, V.; Breusegeme, F.V. ROS signaling: The new wave? Trends Plant Sci. 2011, 16, 300-309. [CrossRef] [PubMed]

24. Miller, G.; Coutu, J.; Shulaev, V.; Mittler, R. Reactive oxygen signaling in plants. Annu. Plant Rev. Online 2018, 33, 189-201.

25. Rekhter, D.; Lüdke, D.; Ding, Y.; Feussner, K.; Zienkiewicz, K.; Lipka, V.; Wiermer, M.; Zhang, Y.L.; Feussner, I. Isochorismate-derived biosynthesis of the plant stress hormone salicylic acid. Science 2019, 365, 498-502. [CrossRef] [PubMed]

26. Glazebrook, J. Contrasting mechanisms of defense against biotrophic and necrotrophic pathogens. Annu. Rev. Phytopathol. 2005, 43, 205-227. [CrossRef] [PubMed]

27. Wasternack, C. Jasmonates: An update on biosynthesis signal transduction and action in plant stress response growth and development. Annu. Bot. 2007, 100, 681-697. [CrossRef]

28. Wasternack, C.; Hause, B. Jasmonates: Biosynthesis perception signal transduction and action in plant stress response growth and development. An update to the 2007 review in Annals of Botany. Annu. Bot. 2013, 111, 1021-1058. [CrossRef]

29. Bilgin, D.D.; Zavala, J.A.; Zhu, J.; Clough, S.J.; Ort, D.R.; DeLucia, E.H. Biotic stress globally downregulates photosynthesis genes. Plant Cell Environ. 2010, 33, 1597-1613. [CrossRef]

30. Chen, Z.; Silva, H.; Klessig, D.F. Active oxygen species in the induction of plant systemic acquired resistance by salicylic acid. Science 1993, 262, 1883-1886. [CrossRef]

31. Durner, J.; Klessig, D.F. Inhibition of ascorbate peroxidase by salicylic acid and 26 -dichloroisonicotinic acid two inducers of plant defense responses. Proc. Natl Acad Sci. USA 1995, 92, 11312-11316. [CrossRef] 
32. Maruta, T.; Noshi, M.; Tanouchi, A.; Tamoi, M.; Yabuta, Y.; Yoshimura, K.; Takahiro Ishikawa, T.; Shigeoka, S. $\mathrm{H}_{2} \mathrm{O}_{2}$-triggered retrograde signaling from chloroplasts to nucleus plays specific role in response to stress. J. Biol. Chem. 2012, 287, 11717-11729. [CrossRef] [PubMed]

33. Balasubramaniam, M.; Kim, B.S.; Hutchens-Williams, H.M.; Loesch-Fries, L.S. The photosystem II oxygen-evolving complex protein PsbP interacts with the coat protein of Alfalfa mosaic virus and inhibits virus replication. Mol. Plant Microbe Interact. 2014, 27, 1107-1118. [CrossRef] [PubMed]

34. Dayakar, B.V.; Lin, H.J.; Chen, C.H.; Ger, M.J.; Lee, B.H.; Pai, C.H.; Chow, D.; Huang, H.E.; Hwang, S.Y.; Chung, M.C.; et al. Ferredoxin from sweet pepper (Capsicum annuum L.) intensifying harpin pss -mediated hypersensitive response shows an enhanced production of active oxygen species (AOS). Plant Mol. Biol. 2003, 51, 913-924. [CrossRef] [PubMed]

35. Huang, H.E.; Ger, M.J.; Yip, M.K.; Chen, C.Y.; Pandey, A.K.; Feng, T.Y. A hypersensitive response was induced by virulent bacteria in transgenic tobacco plants overexpressing a plant ferredoxin-like protein (PFLP). Physiol. Mol. Plant Pathol. 2004, 64, 103-110. [CrossRef]

36. Liau, C.H.; Lu, J.C.; Prasad, V.; Hsiao, H.H.; You, S.J.; Lee, J.T.; Yang, N.S.; Huang, H.E.; Feng, T.Y.; Chen, W.H.; et al. The sweet pepper ferredoxin-like protein (pflp) conferred resistance against soft rot disease in Oncidium Orchid. Transgenic Res. 2003, 12, 329-336. [CrossRef]

37. Tang, K.; Sun, X.; Hu, Q.; Wu, A.; Lin, C.H.; Lin, H.J.; Twyman, R.M.; Christou, P.; Feng, T.Y. Transgenic rice plants expressing the ferredoxin-like protein (AP1) from sweet pepper show enhanced resistance to Xanthomonas oryzae pv. oryzae. Plant Sci. 2001, 160, 1035-1042. [CrossRef]

38. Huang, H.E.; Ger, M.J.; Chen, C.Y.; Pandey, A.K.; Yip, M.K.; Chou, H.W.; Feng, T.Y. Disease resistance to bacterial pathogens affected by the amount of ferredoxin-I protein in plants. Mol. Plant Pathol. 2007, 8, 129-137. [CrossRef]

39. Xu, Y.H.; Liu, R.; Yan, L.; Liu, Z.Q.; Jiang, S.C.; Shen, Y.Y.; Wang, X.F.; Zhang, D.P. Light-harvesting chlorophyll a/b-binding proteins are required for stomatal response to abscisic acid in Arabidopsis. J. Exp. Bot. 2011, 63, 1095-1106. [CrossRef]

40. Jelenska, J.; Yao, N.; Vinatzer, B.A.; Wright, C.M.; Brodsky, J.L.; Greenberg, J.T. A J domain virulence effector of Pseudomonas syringae remodels host chloroplasts and suppresses defenses. Curr. Biol. 2007, 17, 499-508. [CrossRef]

41. Rodríguez-Herva, J.J.; González-Melendi, P.; Cuartas-Lanza, R.; Antúnez-Lamas, M.; Río-Alvarez, I.; Li, Z.; López-Torrejón, G.; Díaz, I.; Del Pozo, J.C.; Chakravarthy, S.; et al. bacterial cysteine protease effector protein interferes with photosynthesis to suppress plant innate immune responses. Cell Microbiol. 2012, 14, 669-681. [CrossRef]

42. Kangasjärvi, S.; Neukermans, J.; Li, S.; Aro, E.M.; Noctor, G. Photosynthesis, photorespiration, and light signaling in defence responses. J. Exp. Bot. 2012, 63, 1619-1636. [CrossRef] [PubMed]

43. Rojas, C.M.; Senthil-Kumar, M.; Tzin, V.; Mysore, K. Regulation of primary plant metabolism during plant-pathogen interactions and its contribution to plant defense. Front. Plant Sci. 2014, 5, 17. [CrossRef] [PubMed]

44. Rojas, C.M.; Senthil-Kumar, M.; Wang, K.; Ryu, C.M.; Kaundal, A.; Mysore, K.S. Glycolate oxidase modulates reactive oxygen species-mediated signal transduction during nonhost resistance in Nicotiana benthamiana and Arabidopsis. Plant Cell 2012, 24, 336-352. [CrossRef] [PubMed]

45. Ahammed, G.J.; Li, X.; Zhang, G.; Zhang, H.; Shi, J.; Pan, C.; Yu, J.; Shi, K. Tomato photorespiratory glycolate-oxidase-derived $\mathrm{H}_{2} \mathrm{O}_{2}$ production contributes to basal defence against Pseudomonas syringae. Plant Cell Environ. 2018, 41, 1126-1138.87. [CrossRef] [PubMed]

46. Bruinsma, J. By how much do land water and crop yields need to increase by 2050. In Proceedings of the FAO Expert Meeting on How to Feed the World in 2050, Rome, Italy, 24-26 June 2009.

47. Conner, R.L.; Kuzyk, A.D.; Su, H. Impact of powdery mildew on the yield of soft white spring wheat cultivars. Can. J. Plant Sci. 2003, 83, 725-728. [CrossRef]

48. Luo, P.G.; Luo, H.Y.; Chang, Z.J.; Zhang, H.Y.; Zhang, M.; Ren, Z.L. Characterization and chromosomal location of Pm40 in common wheat: A new gene for resistance to powdery mildew derived from Elytrigia intermedium. Theor. Appl. Genet. 2009, 118, 1059-1064. [CrossRef]

49. Liu, Z.H.; Xu, M.; Xiang, Z.P.; Li, X.; Chen, W.Q.; Luo, P.G. Registration of the novel wheat lines L658 L693 L696 and L699 with resistance to Fusarium Head blight stripe rust and powdery mildew. J. Plant Regist. 2015, 9, 121-124. [CrossRef] 
50. Shen, X.K.; Ma, L.X.; Zhong, S.F.; Liu, N.; Zhang, M.; Chen, W.Q.; Zhou, Y.L.; Li, H.J.; Chang, Z.J.; $\mathrm{Li}, \mathrm{X}$; et al. Identification and genetic mapping of the putative Thinopyrum intermedium-derived dominant powdery mildew resistance gene PmL962 on wheat chromosome arm 2BS. Theor. Appl. Genet. 2015, 128, 517-528. [CrossRef]

51. Ma, L.X.; Zhong, S.F.; Liu, N.; Chen, W.Q.; Liu, T.G.; Li, X.; Zhang, M.; Ren, Z.L.; Yang, J.Z.; Luo, P.G. Gene expression profile and physiological and biochemical characterization of hexaploid wheat inoculated with Blumeria graminis f. sp. tritici. Physiol. Mol. Plant Pathol. 2015, 90, 39-48. [CrossRef]

52. Liang, Y.P.; Xia, Y.; Chang, X.L.; Gong, G.S.; Yang, J.Z.; Hu, Y.T.; Cahill, M.; Luo, L.Y.; Li, T.; He, L.; et al. Comparative proteomic analysis of wheat carrying Pm40 response to Blumeria graminis f. sp. tritici using two-dimensional electrophoresis. Int. J. Mol. Sci. 2019, 20, 933. [CrossRef]

53. Chang, X.L.; Luo, L.Y.; Liang, Y.P.; Hu, Y.T.; Luo, P.G.; Gong, G.S.; Chen, H.B.; Khaskheli, M.I.; Liu, T.G.; Chen, W.Q.; et al. Papilla formation defense gene expression and HR contribute to the powdery mildew resistance of the novel wheat line L699 carrying Pm40 gene. Physiol. Mol. Plant Pathol. 2019, 106, 208-216. [CrossRef]

54. Hu, Y.T.; Liang, Y.P.; Zhang, M.; Tan, F.Q.; Zhong, S.F.; Li, X.; Gong, G.S.; Chang, X.L.; Shang, J.; Tang, S.W.; et al. Comparative transcriptome profiling of Blumeria graminis $\mathrm{f}$. sp. tritici during compatible and incompatible interactions with sister wheat lines carrying and lacking Pm40. PLoS ONE 2018, 13, e0198891. [CrossRef]

55. Li, J.; Yang, X.; Liu, X.; Yu, H.; Du, C.; Li, M.; He, D. Proteomic analysis of the compatible interaction of wheat and powdery mildew (Blumeria graminis f. sp. tritici). Plant Physiol. Bioch. 2017, 111, 234-243. [CrossRef] [PubMed]

56. Li, Y.; Guo, G.; Zhou, L.; Chen, Y.; Zong, Y.; Huang, J.; Liu, C. Transcriptome analysis identifies candidate genes and functional pathways controlling the response of two contrasting barley varieties to powdery mildew infection. Int. J. Mol. Sci. 2020, 21, 151. [CrossRef]

57. Westermann, A.J.; Lars, B.; Joerg, V. Resolving host-pathogen interactions by dual RNA-seq. PLoS Pathog. 2017, 13, e1006033. [CrossRef]

58. Kuckenberg, J.; Tartachnyk, I.; Noga, G. Temporal and spatial changes of chlorophyll fluorescence as a basis for early and precise detection of leaf rust and powdery mildew infections in wheat leaves. Precis. Agric. 2009, 10, 34-44. [CrossRef]

59. Ajigboye, O.O.; Bousquet, L.; Murchie, E.H.; Ray, R.V. Chlorophyll fluorescence parameters allow the rapid detection and differentiation of plant responses in three different wheat pathosystems. Funct. Plant Boil. 2016, 43, 356-369. [CrossRef] [PubMed]

60. Torres, M.A.; Jones, J.D.; Dangl, J.L. Reactive oxygen species signaling in response to pathogens. Plant Physiol. 2006, 141, 373-378. [CrossRef] [PubMed]

61. Lamb, C.; Dixon, R.A. The oxidative burst in plant disease resistance. Annu. Rev. Plant Biol. 1997, 48, 251-275. [CrossRef]

62. Nishimura, M.T.; Dangl, J.L. Arabidopsis and the plant immune system. Plant J. 2010, 61, 1053-1066. [CrossRef]

63. Shetty, N.P.; Jørgensen, H.J.L.; Jensen, J.D.; Collinge, D.B.; Shetty, H.S. Roles of reactive oxygen species in interactions between plants and pathogens. Eur. J. Plant Pathol. 2008, 121, 267-280. [CrossRef]

64. Hu, X.; Bidney, D.L.; Yalpani, N.; Duvick, J.P.; Crasta, O.; Folkerts, O.; Lu, G.H. Overexpression of a gene encoding hydrogen peroxide-generating oxalate oxidase evokes defense responses in sunflower. Plant Physiol. 2003, 133, 170-181. [CrossRef] [PubMed]

65. Lane, B.G. Oxalate germins and higher-plant pathogens. IUBMB Life 2002, 53, 67-75. [CrossRef] [PubMed]

66. Schulze-Lefert, P.; Vogel, J. Closing the ranks to attack by powdery mildew. Trends Plant Sci. 2000, 5, 343-348. [CrossRef]

67. Polidoros, A.N.; Mylona, P.V.; Scandalios, J.G. Transgenic tobacco plants expressing the maize Cat2 gene have altered catalase levels that affect plant-pathogen interactions and resistance to oxidative stress. Transgenic Res. 2001, 10, 555-569. [CrossRef] [PubMed]

68. Liu, G.; Sheng, X.; Greenshields, D.L.; Ogieglo, A.; Kaminskyj, S.; Selvaraj, G.; Wei, Y.D. Profiling of wheat class III peroxidase genes derived from powdery mildew-attacked epidermis reveals distinct sequence-associated expression patterns. Mol. Plant Microbe Interact. 2005, 18, 730-741. [CrossRef]

69. Torres, M.A.; Dangl, J.L. Functions of the respiratory burst oxidase in biotic interactions, abiotic stress and development. Curr. Opin. Plant Biol. 2005, 8, 397-403. [CrossRef] 
70. Torres, M.A.; Jones, J.D.; Dangl, J.L. Pathogen-induced, NADPH oxidase-derived reactive oxygen intermediates suppress spread of cell death in Arabidopsis thaliana. Nat. Genet. 2005, 37, 1130-1134. [CrossRef]

71. Yoshioka, H.; Numata, N.; Nakajima, K.; Katou, S.; Kawakita, K.; Rowland, O.; Jones, J.D.G.; Doke, N. Nicotiana benthamiana gp91 ${ }^{\text {phox }}$ homologs NbrbohA and NbrbohB participate in $\mathrm{H}_{2} \mathrm{O}_{2}$ accumulation and resistance to Phytophthora infestans. Plant Cell 2003, 15, 706-718. [CrossRef]

72. Torres, M.A.; Dangl, J.L.; Jones, J.D. Arabidopsis gp ${ }^{91 \text { phox }}$ homologues AtrbohD and AtrbohF are required for accumulation of reactive oxygen intermediates in the plant defense response. Proc. Natl. Acad. Sci. USA 2002, 99, 517-522. [CrossRef]

73. Scharte, J.; Schon, H.; Weis, E. Photosynthesis and carbohydrate metabolism in tobacco leaves during an incompatible interaction with Phytophthora nicotianae. Plant Cell Environ. 2005, 28, 1421-1435. [CrossRef]

74. Swarbrick, P.J.; Schulze-Lefert, P.; Scholes, J.D. Metabolic consequences of susceptibility and resistance (race-specific and broad-spectrum) in barley leaves challenged with powdery mildew. Plant Cell Environ. 2006, 29, 1061-1076. [CrossRef] [PubMed]

75. Díaz-Vivancos, P.; Clemente-Moreno, M.J.; Rubio, M.; Olmos, E.; García, J.A.; Martínez-Gómez, P.; Hernández, J.A. Alteration in the chloroplastic metabolism leads to ROS accumulation in pea plants in response to plum pox virus. J. Exp. Bot. 2008, 59, 2147-2160. [CrossRef] [PubMed]

76. Bonfig, K.B.; Schreiber, U.; Gabler, A.; Roitsch, T.; Berger, S. Infection with virulent and avirulent P. syringae strains differentially affects photosynthesis and sink metabolism in Arabidopsis leaves. Planta 2006, 225, 1-12. [CrossRef] [PubMed]

77. Sharkey, T.D.; Bernacchi, C.J.; Farquhar, G.D.; Singsaas, E.L. Fitting photosynthetic carbon dioxide response curves for C3 leaves. Plant Cell Environ. 2007, 30, 1035-1040. [CrossRef]

78. Gerganova, M.; Popova, A.V.; Stanoeva, D.; Velitchkova, M. Tomato plants acclimate better to elevated temperature and high light than to treatment with each factor separately. Plant Physiol. Bioch. 2016, 104, 234-241. [CrossRef]

79. Brugger, A.; Kuska, M.T.; Mahlein, A.K. Impact of compatible and incompatible barley-Blumeria graminis $\mathrm{f}$. sp. hordei interactions on chlorophyll fluorescence parameters. J. Plant Dis. Protect. 2018, 125, 177-186.

80. Göhre, V.; Jones, A.M.; Sklenář, J.; Robatzek, S.; Weber, A.P. Molecular crosstalk between PAMP-triggered immunity and photosynthesis. Mol. Plant Microbe Interact. 2012, 25, 1083-1092. [CrossRef]

81. Rolfe, S.A.; Scholes, J.D. Chlorophyll fluorescence imaging of plant-pathogen interactions. Protoplasma 2010, 247, 163-175. [CrossRef]

82. Backer, R.; Naidoo, S.; van den Berg, N. The nonexpressor of pathogenesis-related genes 1 (NPR1) and related Family: Mechanistic insights in plant disease resistance. Front. Plant Sci. 2019, 10, 102. [CrossRef]

83. Broekgaarden, C.; Caarls, L.; Vos, I.A.; Pieterse, C.M.; Van Wees, S.C. Ethylene: Traffic controller on hormonal crossroads to defense. Plant Physiol. 2015, 169, 2371-2379. [CrossRef] [PubMed]

84. Van der Ent, S.; Van Wees, S.C.; Pieterse, C.M. Jasmonate signaling in plant interactions with resistance-inducing beneficial microbes. Phytochemistry 2009, 70, 1581-1588. [CrossRef] [PubMed]

85. Cao, H.; Glazebrook, J.; Clarke, J.D.; Volko, S.; Dong, X. The Arabidopsis NPR1 gene that controls systemic acquired resistance encodes a novel protein containing ankyrin repeats. Cell 1997, 88, 57-63. [CrossRef]

86. Wu, Y.; Zhang, D.; Chu, J.Y.; Boyle, P.; Wang, Y.; Brindle, I.D.; Luca, V.D.; Després, C. The Arabidopsis NPR1 protein is a receptor for the plant defense hormone salicylic acid. Cell Rep. 2012, 1, 639-647. [CrossRef] [PubMed]

87. Zhang, J.Y.; Qiao, Y.S.; Lv, D.; Gao, Z.H.; Qu, S.C.; Zhang, Z. Malus hupehensis NPR1 induces pathogenesis-related protein gene expression in transgenic tobacco. Plant Biol. 2012, 14, 46-56. [CrossRef]

88. Chen, X.K.; Zhang, J.Y.; Zhang, Z.; Du, X.L.; Du, B.B.; Qu, S.C. Overexpressing MhNPR1 in transgenic Fuji apples enhances resistance to apple powdery mildew. Mol. Boil. Rep. 2012, 39, 8083-8089. [CrossRef]

89. Wang, Z.; Ma, L.Y.; Li, X.; Zhao, F.Y.; Sarwar, R.; Cao, J.; Li, Y.L.; Ding, L.N.; Zhu, K.M.; Yang, Y.H.; et al. Genome-wide identification of the NPR1-like gene family in Brassica napus and functional characterization of BnaNPR1 in resistance to Sclerotinia sclerotiorum. Plant Cell Rep. 2020, 39, 709-722. [CrossRef]

90. Wang, C.S.; Huang, J.C.; Hu, J.H. Characterization of two subclasses of PR-10 transcripts in lily anthers and induction of their genes through separate signal transduction pathways. Plant Mol. Biol. 1999, 40, 807-814. [CrossRef] 
91. Colditz, F.; Niehaus, K.; Krajinski, F. Silencing of PR-10-like proteins in Medicago truncatula results in an antagonistic induction of other PR proteins and in an increased tolerance upon infection with the oomycete Aphanomyces euteiches. Planta 2007, 226, 57-71. [CrossRef]

92. Sudisha, J.; Sharathchandra, R.G.; Amruthesh, K.N.; Kumar, A.; Shetty, H.S. Pathogenesis related proteins in plant defense response. In Plant Defence: Biological Control. Progress in Biological Control; Mérillon, J., Ramawat, K., Eds.; Springer: Dordrecht, Germany, 2012; Volume 12, pp. 379-403.

93. Ahmed, S.M.; Liu, P.; Xue, Q.; Ji, C.; Qi, T.; Guo, J.; Guo, J.; Kang, Z.S. TaDIR1-2 a wheat ortholog of lipid transfer protein AtDIR1 contributes to negative regulation of wheat resistance against Puccinia striiformis $\mathrm{f}$. sp. tritici. Front. Plant Sci. 2017, 8, 521. [CrossRef]

94. Wang, C.F.; Huang, L.L.; Buchenauer, H.; Han, Q.M.; Zhang, H.C.; Kang, Z.S. Histochemical studies on the accumulation of reactive oxygen species $\left(\mathrm{O}^{2-}\right.$ and $\left.\mathrm{H}_{2} \mathrm{O}_{2}\right)$ in the incompatible and compatible interaction of wheat-Puccinia striiformis f. sp. tritici. Physiol. Mol. Plant Pathol. 2007, 71, 230-239. [CrossRef]

95. Kim, D.; Langmead, B.; Salzberg, S.L. HISAT: A fast-spliced aligner with low memory requirements. Nat. Methods 2015, 12, 357-360. [CrossRef] [PubMed]

96. Apweiler, R.; Bairoch, A.; Wu, C.H.; Barker, W.C.; Boeckmann, B.; Ferro, S.; Gasteiger, E.; Huang, H.Z.; Lopez, R.; Magrane, M.; et al. UniProt: The universal protein knowledgebase. Nucleic Acids Res. 2004, 32, D115-D119. [CrossRef] [PubMed]

97. Pertea, M.; Pertea, G.M.; Antonescu, C.M.; Chang, T.C.; Mendell, J.T.; Salzberg, S.L. StringTie enables improved reconstruction of a transcriptome from RNA-seq reads. Nat. Biotechnol. 2015, 33, 290-295. [CrossRef] [PubMed]

98. Robinson, M.D.; McCarthy, D.J.; Smyth, G.K. edgeR: A Bioconductor package for differential expression analysis of digital gene expression data. Bioinformatics 2010, 26, 139-140. [CrossRef]

99. Livak, K.J.; Schmittgen, T.D. Analysis of relative gene expression data using real-time quantitative PCR and the $2^{-\Delta \Delta C T}$ method. Methods 2001, 25, 402-408. [CrossRef]

100. Faheem, M.; Li, Y.B.; Arshad, M.; Cheng, J.Y.; Jia, Z.; Wang, Z.K.; Xiao, J.; Wang, H.Y.; Cao, A.Z.; Xing, L.P.; et al. A disulphide isomerase gene $(P D I-V)$ from Haynaldia villosa contributes to powdery mildew resistance in common wheat. Sci. Rep. 2016, 6, 24227. [CrossRef]

101. Scholtz, J.J.; Visser, B. Reference gene selection for qPCR gene expression analysis of rust-infected wheat. Physiol. Mol. Plant Pathol. 2013, 81, 22-25. [CrossRef] 